\title{
Theoretical and Experimental Studies on Early Transition Metal Nitrides for Thermoelectrics
}

\author{
Mohammad Amin Gharavi
}


Linköping Studies in Science and Technology

Dissertation No. 2031

\section{Theoretical and experimental studies on early transition metal nitrides for thermoelectrics}

\section{Mohammad Amin Gharavi}

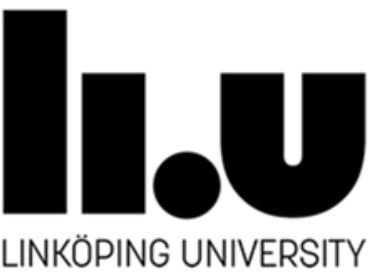

Thin Film Physics Division,

Department of Physics, Chemistry and Biology (IFM)

Linköping University, SE-581 83 Linköping, Sweden

Linköping 2019 
Thin Film Physics Division,

Department of Physics, Chemistry and Biology (IFM),

Linköping University, SE-581 83 Linköping, Sweden

Cover image

Front side:

Low-resolution TEM image of rock-salt cubic $111 \mathrm{CrN}$ thin film deposited on ccut sapphire substrate. The nanometer sized nanoinclusions are hexagonal $\mathrm{Cr}_{2} \mathrm{~N}$ which may form as a secondary phase in $\mathrm{CrN}$ hard coatings or stainless-steel.

\section{Back side:}

High-resolution TEM image of a single-crystal $\mathrm{Cr}_{2} \mathrm{~N}$ thin film deposited on a ccut sapphire substrate resulting in a $(1 \overline{2} 10)(0001) \mathrm{Cr}_{2} \mathrm{~N} / /(1 \overline{2} 10)(0001) \mathrm{Al}_{2} \mathrm{O}_{3}$ and $[1 \overline{1} 00] \mathrm{Cr}_{2} \mathrm{~N} / /[1 \overline{1} 00] \mathrm{Al}_{2} \mathrm{O}_{3}$ epitaxial relationship.

(C) Mohammad Amin Gharavi, 2019

ISBN: 978-91-7929-964-4

ISSN: 0345-7524

Printed by LiU-Tryck, Linköping, Sweden, 2019 


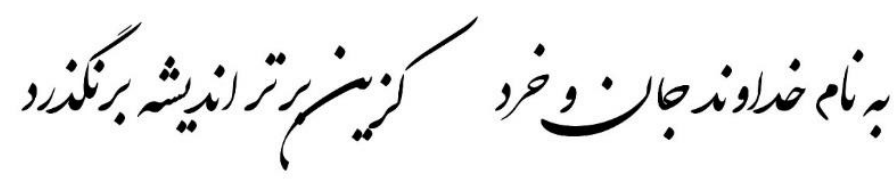

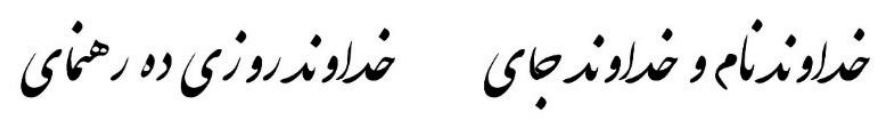

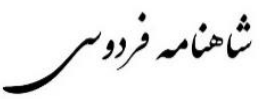

In the name of the lord of bath wisdom and mind

7 nothing sublimer can thought be applied

The lord of whatever is named or assigned

A place, the sustainer of all and the quide

The Persian epic "The Book of Kings"

Abu' '-2asim Ferdousi 7usi

$10^{\text {th }}$ century A.D. 


\section{Abstract}

Thermoelectricity transforms temperature gradients across thermoelectric material into an external voltage through a phenomenon known as the Seebeck effect. This property has resulted in niche applications such as solid-state cooling for electronic and optoelectronic devices which exclude the need for a coolant or any moving parts and long-lasting, maintenance-free radioisotope thermoelectric generators used for deep-space exploration. However, the high price and low efficiency of thermoelectric generators have prompted scientists to search for new materials and/or methods to improve the efficiency of the already existing ones. Thermoelectric efficiency is governed by the dimensionless figure of merit $z T$, which depends on the electrical conductivity, thermal conductivity and Seebeck coefficient value of the material and has rarely surpassed unity.

In order to address these issues, research conducted on early transition metal nitrides spearheaded by cubic scandium nitride $(\mathrm{ScN})$ thin films showed promising results with high power factors close to $3000 \mu \mathrm{Wm}^{-1} \mathrm{~K}^{-2}$ at $500{ }^{\circ} \mathrm{C}$. These results are the main motivation behind my thesis where the conducted research is separated into two different routes:

- the synthesis and characterization of chromium nitride thin films and its alloys

- the study of hypothetical ternary nitrides equivalent to scandium nitride

Rock-salt cubic chromium nitride $(\mathrm{CrN})$ deposited in the form of thin films by reactive magnetron sputtering was chosen for its large Seebeck coefficient of approximately $-200 \mu \mathrm{V} / \mathrm{K}$ and low thermal conductivity between 2 and 4 $\mathrm{Wm}^{-1} \mathrm{~K}^{-1}$. The results show that $\mathrm{CrN}$ in single crystal form has a low electrical resistivity below $1 \mathrm{~m} \Omega \mathrm{cm}$, a Seebeck coefficient value of $-230 \mu \mathrm{V} / \mathrm{K}$ and a power factor close to $5000 \mu \mathrm{Wm}^{-1} \mathrm{~K}^{-2}$ at room temperature. These promising results could lead to $\mathrm{CrN}$ based thermoelectric modules which are cheaper and more stable compared to traditional thermoelectric material such as bismuth telluride $\left(\mathrm{Bi}_{2} \mathrm{Te}_{3}\right)$ and lead telluride $(\mathrm{PbTe})$.

Although cubic $\mathrm{CrN}$ has been shown to be a promising material for research with a large power factor, the electrical resistivity limits applications in pure form as the $z T$ is estimated to be slightly below 0.5 . To overcome this issue, I enhanced the thermoelectric power-factor of $\mathrm{CrN}$ by alloying it with a conductor, Rock-salt cubic vanadium nitride (VN). $\mathrm{VN}$ is a suitable choice as both materials share the same crystal structure and have almost equal lattice constants. Through deposition at $720{ }^{\circ} \mathrm{C}$, where a small amount of $\mathrm{VN}$ (less than $5 \%$ ) and $\mathrm{Cr}_{2} \mathrm{~N}$ is introduced into the film, a reduced electrical resistivity averaged around $0.8 \times 10^{-3} \Omega \mathrm{cm}$, Seebeck coefficient value of $270 \mu \mathrm{V} / \mathrm{K}$ and a power-factor of $9.1 \times 10^{-3} \mathrm{~W} / \mathrm{mK} 2$ is measured at room temperature, which surpasses the thermoelectric properties of 
$\mathrm{Bi}_{2} \mathrm{Te}_{3}$. Hexagonal dichromium nitride $\left(\mathrm{Cr}_{2} \mathrm{~N}\right)$ nano-inclusions increase the charge carrier concentration and act as phonon scattering sites. Single crystal $\mathrm{Cr}_{2} \mathrm{~N}$ was also studied separately, as it shows interesting elastic-plastic mechanical properties and high resistance to oxidation at high temperatures for long periods of time.

In the second part of this thesis, hypothetical ternary nitrides equivalent to $\mathrm{ScN}$ are investigated for their prospective thermoelectric properties. Scandium nitride has a relatively high thermal conductivity value (close to $10 \mathrm{Wm}^{-1} \mathrm{~K}^{-1}$ ), resulting in a low $z T$. A hypothetical ternary equivalent to $\mathrm{ScN}$ may have a similar electronic band structure and large power factor, but with a lower thermal conductivity value leading to better thermoelectric properties. Thus, the elements magnesium, titanium, zirconium, and hafnium were chosen for this purpose. DFT calculations were used to simulate $\mathrm{TiMgN}_{2}, \mathrm{ZrMgN}_{2}$ and $\mathrm{HfMgN}_{2}$. The results show the $\mathrm{MeMgN}_{2}$ stoichiometry to be stable, with two rivaling crystal structures: trigonal $\mathrm{NaCrS}_{2}$ and monoclinic $\mathrm{LiUN}_{2}$. The calculated electronic band structure of these compounds shows a direct band-gap for the monoclinic and an indirect band-gap for the trigonal crystal structures. These findings, coupled with predicted Seebeck coefficient values, encourages actual synthesis of such materials. DFT calculations were also used to study ( $\mathrm{Zr}, \mathrm{Mg}) \mathrm{N}$ and (Hf, Mg)N alloys based on the SQS model. The transition temperature between the ordered monoclinic structure of $\mathrm{ZrMgN}_{2}$ and $\mathrm{HfMgN}_{2}$ and the disordered $(\mathrm{Zr}, \mathrm{Mg}) \mathrm{N}$ and (Hf, $\left.\mathrm{Mg}\right) \mathrm{N}$ alloys is calculated to be approximately $800 \mathrm{~K}$ and $1050 \mathrm{~K}$ respectively. Density of State (DoS) calculations show that similar to $(\mathrm{Ti}, \mathrm{Mg}) \mathrm{N},(\mathrm{Zr}, \mathrm{Mg}) \mathrm{N}$ and $(\mathrm{Hf}, \mathrm{Mg}) \mathrm{N}$ are also semiconducting. The thermoelectric properties of both compounds are also predicted, and that in the range of a moderate change in the Fermi level, high Seebeck coefficient values at room temperature can be achieved.

Finally, in order to complete the mentioned study on hypothetical ternaries, I deposited ( $\mathrm{Ti}, \mathrm{Mg}) \mathrm{N}$ thin film alloys by reactive magnetron sputtering. These films, which were deposited at $400{ }^{\circ} \mathrm{C}$, are porous and are crystallized in the rocksalt cubic structure. As-deposited films show an electrical resistivity of $150 \mathrm{~m} \Omega \mathrm{cm}$ and a Seebeck coefficient of $-25 \mu \mathrm{V} / \mathrm{K}$, which shows semiconducting properties. In order to initiate a phase transformation, these films when annealed at approximately $800^{\circ} \mathrm{C}$, where nano-inclusions of a titanium/magnesium oxynitride are formed in a $\mathrm{LiTiO}_{2}$-type superstructure are identified by XRD and TEM analysis. 


\section{Populärvetenskaplig Sammanfattning}

Materialvetenskap handlar om studier av organiska och oorganiska föreningar som strukturerar vår moderna civilisation. Ett primärt mål för sådana studier, förutom att söka grundläggande kunskap, är att hitta lämpliga tillämpningar. En av de främsta prioriteringarna inom materialforskning är energisektorn. Världens energiförbrukning har ökat från 20000 TWh per år sedan 1930-talet till ett förutspått värde på 210000 TWh per år före 2030. På grund av begränsade resurser och ökade priser är effektivare energiproduktion, distribution och konsumtion viktigt. Till detta ska läggas bekymmer ur miljösynpunkt, till exempel avskogning, föroreningar och global uppvärmning (med ett nuvarande koldioxidfotavtryck på över 33 miljarder ton per år).

Termoelektriska komponenter omvandlar värme till elektrisk energi genom en process som kallas Seebeck-effekten. Detta görs genom att applicera en termisk gradient över ett termoelektriskt material, som vanligtvis är en halvledare med en hög Seebeck-koefficient, men låg elektrisk och värmeledningsförmåga. Ett sådant material kan användas för att minska bränsleförbrukningen genom att återvinna spillvärme och därmed vara till nytta för både miljö och ekonomi. När termoelektriska komponenter används för att omvandla energi genom att applicera en extern spänning på ett termoelektriskt material (Peltier-effekten) skapas en temperaturgradient med en ände av det termoelektriska elementet uppvärmd medan den andra änden kyls ner. Detta möjliggör en kompakt och underhållsfri kyldesign.

Andra tillämpningar som använder termoelektriska material innefattar högtemperatursensorer för turbinblad, konstgjord hud, kylning i elektronik, lokaliserade kraftkällor och radioisotop-termoelektriska-generatorer (RTG) som används i djupgående satelliter. Men de här förutspådda breda tillämpningarna kräver att man studerar nya material, eftersom de nu använda aktuella termoelektriska materialen är dyra, sällsynta, ibland giftiga, och ger generatorer med låg uteffektivitet.

Denna avhandling hoppas kunna göra framsteg när det gäller att studera termoelektriska material genom att introducera nya övergångsmetallnitrider som ersättning för traditionella termoelektriskt material. Övergångsmetallitrider är kända för god mekanisk, termisk och kemisk stabilitet och studier av halvledande TM nitrider för framtida termoelektriska egenskaper kan leda till nytt material med högre effektivitet jämfört med traditionellt material. 


\section{Preface}

This thesis is a summary of my $\mathrm{PhD}$ studies at the Thin Film Physics Division (Energy Materials Unit) of the Department of Physics, Chemistry and Biology (IFM) at Linköping University from September 2014 to November 2019 and is based on my licentiate thesis published in May 2017:

"Nitride Thin Films for Thermoelectric Applications: Synthesis, Characterization and Theoretical Predictions" (Linköping Studies in Science and Technology, Licentiate Thesis No. 1774).

The aim of this thesis is to synthesize and study novel nitride semiconducting thin films (i.e., rock-salt cubic chromium nitride) and to simulate hypothetical ternary compounds which have prospective thermoelectric properties.

This research is financially supported by the European Research Council under the European Community's Seventh Framework Programme (FP/2007-2013)/ERC grant agreement no. 335383, the Swedish Government Strategic Research Area in Materials Science on Functional Materials at Linköping University (Faculty Grant SFO-Mat-LiU No. 2009 00971), the Swedish Foundation for Strategic Research (SSF) through the Future Research Leaders 5 and 6 programs, and the Swedish Research Council (VR) under project no. 621-2012-4430 and no 2016-03365 including through International Career Grant No. 330-2014-6336 and No. 201604810 by the Swedish e-Science Research Centre (SeRC). Also, the Marie Sklodowska Curie Actions, Cofund, Project INCA 600398, is gratefully acknowledged. In addition, the Swedish National Infrastructure for Computing (SNIC) provided access to the necessary supercomputer resources located at the National Supercomputer Center (NSC).

During the course of research underlying this thesis, I was enrolled in Agora Materiae, a multidisciplinary doctoral program at Linköping University, Sweden. I was also an active member of the PhD Reference group, where I also was the student representative for the Equal Opportunities group, acting towards a better work environment for the PhD students studying at IFM. 


\section{Acknowledgments}

Whether it is mankind's never-ending quest for knowledge or the daily life of an individual, a large part of our success is due to our predecessors paving the way for us, and in many cases, without receiving or even expecting anything in return.

This thesis would not have been realized without the help and guidance I received from my family, friends, teachers and colleagues. Thus, I would like to express my gratitude and many thanks to all of them.

First and foremost, I would like to thank my supervisor Per Eklund, who gave me the opportunity to expand my knowledge in material sciences, train with new equipment and techniques, and encouraged my creativity in the lab by granting me this fantastic opportunity and paving the way for a professional career in materials science.

Many thanks to my co-supervisors Björn Alling and Rickard Armiento. You introduced me to DFT and gave my thesis a theoretical perspective, enhancing it to a higher scientific level that I would have never achieved on my own.

I would also like to thank my previous co-supervisor Camille Pallier, the former head of Agora Materiae Per-Olof Holtz, and my mentor Peter Nilsson for the contribution they had on my studies as a PhD student.

Special thanks to Jens Birch, for managing the dynamic atmosphere of the Thin Film Physics division.

I must also acknowledge my dear friend, Fredrik Eriksson. A great teacher, cheerful and patient researcher, you were always available when I needed your help during my work.

Special thanks to all my co-authors, especially Jun Lu and Arnaud le Febvrier, for their outstanding lab skills and valuable contribution to my research.

Many thanks to Thomas Lingefelt, Harri Savimäki, Therese Dannetun, Anette

Frid, Åsa Rybo Landelius and other administrative staff and technical support for their outstanding behind the scenes work done at the department.

I would also like to express my many thanks to Reza Yazdi, Babak Bakhit, David Engberg, Biplab Paul, Mahdi Morsali, Ahmed El Gazaly, Javad Jafari, Misagh Ghezellou, Lida Khajavi, Bilal Syed and many more friends at IFM, Agora Materiae and the Energy Materials Unit. 
And at the end I would like to thank my parents, family and relatives, especially my wife, Sepideh Adibi and my daughter Tarannom.

Truly this experience is a memory I will cherish forever.

Mohammad Amin Gharavi

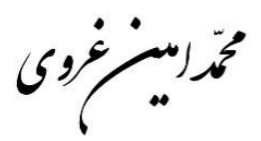

Linköping. November 2019 


\section{List of included papers}

Paper I

\section{Microstructure and thermoelectric properties of $\mathrm{CrN}$ and $\mathrm{CrN} / \mathrm{Cr}_{2} \mathrm{~N}$ thin films}

M. A. Gharavi, S. Kerdsongpanya, S. Schmidt, F. Eriksson, N. V. Nong, J. Lu, B. Balke, D. Fournier, L. Belliard, A. le Febvrier, C. Pallier and P. Eklund

J. Phys. D: Appl. Phys. 51: 355302 (2018)

\section{Author's contribution:}

I planned and coordinated the experiments and performed all the depositions. I characterized the samples with SEM and XRD, and participated in the TEM, AFM and thermoelectric characterization. I analyzed the data and wrote the manuscript.

Paper II

\section{Synthesis and characterization of single-phase epitaxial $\mathrm{Cr}_{2} \mathrm{~N}$ thin films by reactive magnetron sputtering}

M. A. Gharavi, G. Greczynski, F. Eriksson, J. Lu, B. Balke, D. Fournier, A. le Febvrier,

C. Pallier and P. Eklund

J. Mater. Sci. 54: 1434-1442 (2019)

\section{Author's contribution:}

I planned and coordinated the experiments and performed all the depositions. I characterized the samples with SEM and XRD, and participated in the TEM, XPS and thermoelectric characterization. I analyzed the data and wrote the manuscript. 
Paper III

High thermoelectric power-factor with enhanced electrical conductivity of chromium nitride thin films by vanadium doping

M. A. Gharavi, D. Gambino, A. le Febvrier, F. Eriksson, R. Armiento, B. Alling and P. Eklund

Manuscript in final preparation

\section{Author's contribution:}

I planned and coordinated the experiments and performed all the depositions. I characterized the samples with SEM, XRD and investigated the Seebeck coefficient and electrical resistivity. I analyzed the data and wrote the manuscript.

Paper IV

Theoretical study of phase stability, crystal and electronic structure of $\mathrm{MeMgN}_{2}(\mathrm{Me}=\mathrm{Ti}, \mathrm{Zr}, \mathrm{Hf})$ compounds

M. A. Gharavi, R. Armiento, B. Alling and P. Eklund

J. Mater. Sci. 53: 4294-4305 (2018)

\section{Author's contribution:}

I was responsible for the project planning and discussions. I performed the calculations and was responsible for evaluation and interpretation. I organized the content and wrote the manuscript. 
Paper V

Theoretical Study of the Phase Transitions and Electronic Structure of $\left(\mathrm{Zr}_{0.5}\right.$, $\left.\mathrm{Mg}_{0.5}\right) \mathrm{N}$ and $\left(\mathrm{Hf}_{0.5}, \mathrm{Mg}_{0.5}\right) \mathrm{N}$

M. A. Gharavi, R. Armiento, B. Alling and P. Eklund

Manuscript in final preparation

\section{Author's contribution:}

I was responsible for the project planning and discussions. I performed the calculations and was responsible for evaluation and interpretation. I organized the content and wrote the manuscript.

Paper VI

Phase Transformation and Superstructure Formation in $\left(\mathrm{Ti}_{0.5}, \mathrm{Mg}_{0.5}\right) \mathrm{N}$ Thin Films Through High-Temperature Annealing

M. A. Gharavi, A. le Febvrier, J. Lu, R. Armiento, B. Alling and P. Eklund

Manuscript in final preparation

\section{Author's contribution:}

I planned and coordinated the experiments and performed all the depositions. I characterized the samples with SEM and XRD, studied the thermoelectric properties and participated in the TEM and XPS characterization. I analyzed the data and wrote the manuscript. 


\section{Table of Contents}

1. Introduction ............................................................................. 1

2. Thin film synthesis and characterization ................................... 5

Diode sputter deposition.................................................... 5

Magnetron sputtering .......................................................... 9

Reactive sputtering ........................................................... 12

RF sputtering ....................................................................... 13

3. The microstructural evolution of thin films ............................... 15

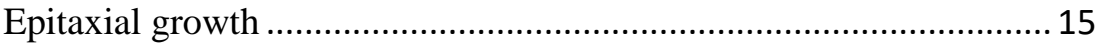

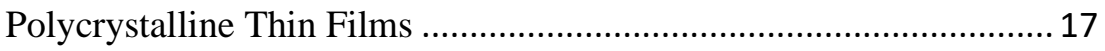

Formation kinetics ............................................................... 17

4. Thermoelectrics: basics and challenges................................ 21

Basics .............................................................................. 22

The Seebeck coefficient .............................................................. 25

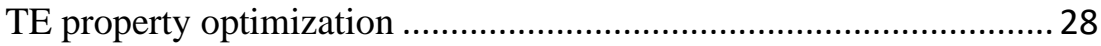

5. Theoretical calculations: phase stability and structure prediction... 33

The Schrödinger equation .......................................................... 33

Density Functional Theory (DFT) ............................................ 34

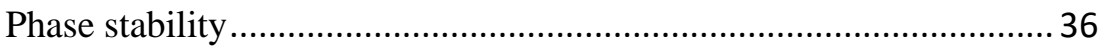

Random alloys and order/disorder phase transformation .................. 39

Simulating equivalent ternaries for scandium nitride ..................... 41

6. Contributions to the field ................................................... 43

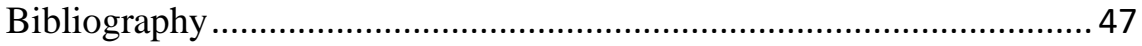

List of included papers ....................................................... 53 


\section{Introduction}

Energy efficiency and greenhouse gas reduction emphasize the need for alternative sources of power generation. One logical approach would be to directly harvest waste heat and to transform it into electrical energy. For this, thermoelectrics can be used. Thermoelectric devices have many industrial applications such as waste heat recycling produced from internal combustion engines and power generation for wearable electronics, to name a few. This property is due to the Seebeck effect, which is the conversion of a thermal gradient across a device into an external voltage. The opposite operation, the Peltier effect, induces a thermal gradient when an electric current is passed through the thermoelectric device. This property can be used for refrigeration without the need of a coolant.

The heart of thermoelectric research is to enhance device efficiency, which is done by maximizing the dimensionless figure of merit, $z T=\frac{\alpha^{2} \sigma}{\kappa} T$, where $\alpha$ is the Seebeck coefficient, $\sigma=1 / \rho$ is the electrical conductivity, $\kappa$ is the thermal conductivity, and $T$ is the absolute temperature. The Carnot engine efficiency is obtained when $z T$ reaches infinity. By maximizing the power factor $\left(\alpha^{2} \sigma\right)$ and minimizing thermal conductivity, the efficiency of a thermoelectric device will increase. However, present thermoelectric devices have a relatively low $z T$ value of approximately unity, as these three parameters are interdependent. For example; it is not possible to increase the $z T$ by simply doping a thermoelectric semiconductor (and increasing $\sigma$ ) as this will decrease $\alpha$ and increase $\kappa$ at the same time. Thus, a balanced approach is needed. In addition, usage of traditional thermoelectric material includes other challenging aspects as well. $\mathrm{Bi}_{2} \mathrm{Te}_{3}$ and $\mathrm{PbTe}$ are well known thermoelectric materials, but the low production of tellurium ${ }^{1}$ ${ }^{2}$ plus the use of toxic elements limits them to niche applications. Such applications include (but are not limited to) solid-state cooling for specialized optoelectronics devices ${ }^{3}{ }^{4}$, radioisotope thermoelectric generators used for deep-space exploration ${ }^{5}$ ${ }^{6}$, and prospective military applications such as thermal camouflaging. ${ }^{78}$

To go beyond this, researchers are studying thermoelectric materials which can be engineered according to the phonon glass - electron crystal (PGEC) approach ${ }^{9}{ }^{10}$, i.e., designing materials where charge carriers will flow freely as in a crystal, but 
the lattice contribution to thermal conductivity is disrupted much like phonon scattering in glass. Nanostructuring, doping, alloying and synthesis of multilayers and superlattices, can simultaneously decrease thermal conductivity and electrical resistivity, resulting in higher $z T$ values.

In this dissertation, my approach for studying novel thermoelectric material is focused on early transition metal nitrides thin films. Transition metal nitrides ${ }^{11} 12$ are well known for their excellent mechanical, chemical and thermal stability and properties, and have been used extensively in metallurgy and hard-coating applications. Titanium has a special place in this regard, with extensive research conducted on $\mathrm{TiN}^{13}{ }^{14}{ }^{15}$, $\mathrm{TiAlN}^{16}$ and $\mathrm{TiSiN}^{17}$ due to the mentioned properties. For this reason, studying early transition metal nitrides with thermoelectric properties, scandium nitride ${ }^{*}$ and chromium nitride, becomes of interest. It is known that rocksalt $\mathrm{ScN}^{18} 192021$ has an approximate power factor of $3000 \mu \mathrm{Wm}^{-1} \mathrm{~K}^{-2}$, which is high for an early transition metal nitride. However, its relatively high thermal conductivity $^{22} 23$ prevents it use as a thermoelectric material in pure form. Experimental research continued by studying rock-salt cubic chromium nitride (CrN) thin films. ${ }^{24}{ }^{25}$ Based on the strict definition, $\mathrm{CrN}$ is the only transition metal nitride with semiconducting properties, ${ }^{26}{ }^{27} 28{ }^{29}$ (when above the Néel temperature ${ }^{30}$ ) and thus it can become of interest for thermoelectric research. $\mathrm{CrN}$ is a well-known hard coating with good high-temperature mechanical and chemical stability. ${ }^{31}{ }^{32}$ Thermoelectric measurements (discussed in paper I) have shown Seebeck coefficient values of $-230 \mu \mathrm{V} / \mathrm{K}$. Under-stoichiometric single crystal CrN films are shown to have a resistivity below $1 \mathrm{~m} \Omega \mathrm{cm}$ resulting in power factors close to $5000 \mu \mathrm{Wm}^{-1} \mathrm{~K}^{-2}$ at room temperature. Similar to $\mathrm{ScN}^{33}{ }^{34}, \mathrm{CrN}$ can even be made p-type under some conditions. ${ }^{35}$ Polycrystalline bulk samples of $\mathrm{CrN}^{36}{ }^{37}$ have also been prepared where the thermoelectric properties can be tuned through alloying with other transition metal elements such as tungsten. $\mathrm{CrN}$ is known to have an anomalously low thermal conductivity ${ }^{38} 39$ (compared to other TM nitrides) of approximately $2-4 \mathrm{Wm}^{-1} \mathrm{~K}^{-1}$, which is attributed to the localized $3 d$ orbitals which give the electrons large effective masses and consequently low thermal conductivity.

\footnotetext{
* According to the strict definition, scandium is not a transition metal as its ionized state $\left(\mathrm{Sc}^{3+}\right)$ does not have partially filled d-orbitals (the same goes for zinc as well). However, due to its similar properties compared to other early transition metals, a laxer definition is usually adopted when discussing scandium.
} 
The research presented in this dissertation is divided into two subcategories:

1. Experimental research on the thermoelectric properties of $\mathrm{CrN}$ thin films and alloys. These thin films are deposited by reactive magnetron sputtering, which have the benefit of good control over the crystal quality and phase purity of the films.

2. Theoretical and experimental studies of hypothetical ternary nitrides equivalent to $\mathrm{ScN}$ by utilizing first-principles calculations. It is assumed that compared to a binary compound, equivalent ternaries composed of heavy elements should have a similar electronic band structure but with a lower thermal conductivity, thus the crystal structure would be more effective in phonon scattering without hindering the charge carrier conduction. Such theoretical methods coupled with modern computers will allow fast simulations of an equivalent ternary to any known binary semiconductor. By constructing phase diagrams and choosing any hypothetically stable compound for band structure calculations, experimentalists can with a much higher degree of confidence choose appropriate material systems for research.

In the first section, the thermoelectric properties of $\mathrm{CrN}$ is studied in paper I through synthesizing substoichiometric films and controlling the metallic $\mathrm{Cr}_{2} \mathrm{~N}$ phase impurities which form as nanoinclusions.

Paper II provides a more in-depth look at $\mathrm{Cr}_{2} \mathrm{~N}$ by synthesizing phase pure epitaxial films. Physical properties such as hardness, elasticity, electric, and thermal conductivity are studied, and oxidation resistance tests are performed.

In paper III, the experience gained from paper I is used to enhance the thermoelectric properties of $\mathrm{CrN}$ to an even larger extent, by introducing a small amount $\mathrm{Cr}_{2} \mathrm{~N}$ nanoinclusions and vanadium doping resulting in $(\mathrm{Cr}, \mathrm{V}) \mathrm{N}$ thin film solid solutions.

For the theoretical part of my research, scandium nitride $(\mathrm{ScN})$ was chosen as an appropriate thermoelectric group three nitride for simulating novel TE material. By using density functional theory (DFT), it is possible to predict a hypothetical equivalent ternary composed of group two alkaline earth and group four early transition metal nitrides. If successful, such ternaries could be synthesized experimentally and tested for any potential thermoelectric properties. This study is 
reported in paper IV, where the phase stability, electronic band structure, and thermoelectric properties of $\mathrm{TiMgN}_{2}, \mathrm{ZrMgN}_{2}$, and $\mathrm{HfMgN}_{2}$ are studied.

Paper V is a continuation of the research done in paper IV. Here I continue with the study of $(\mathrm{Zr}, \mathrm{Mg}) \mathrm{N}$ and $(\mathrm{Hf}, \mathrm{Mg}) \mathrm{N}$ solid solutions by calculating the order/disorder transition temperature and the density of states.

Finally, the study conducted in paper VI is an actual attempt to synthesize $\mathrm{TiMgN}_{2}$. To accomplish this, (Ti, Mg)N solid-solution thin films were deposited by magnetron sputtering. After studying the properties of the as-deposited films, (Ti, $\mathrm{Mg}) \mathrm{N}$ is annealed at $800{ }^{\circ} \mathrm{C}$ for 1 hour. The results are then studied both by X-ray diffraction and transmission electron microscopy. 


\section{Thin film synthesis and characterization}

Synthesis of nanostructured materials and thin films ${ }^{40}$ can be done by many techniques. For example, synthesis and fabrication by ball milling and electrodeposition have shown to be suitable for scaling up to the industrial level while being affordable and easy to handle. On the other hand, versatile methods such as molecular beam epitaxy and pulsed laser deposition which can prepare precise samples in $0 \mathrm{D}, 1 \mathrm{D}$, and $2 \mathrm{D}$ morphologies are usually more complicated and expensive and are suitable for laboratory research. Some techniques are both cheap enough for industrial scale mass production while at the same time capable of producing research-quality samples. Sputter deposition is one of these methods. This section discusses the basics of sputter deposition and some of the concepts in utilizing the technique.

\section{Diode sputter deposition}

Sputter deposition was first reported by W. R. Grove ${ }^{41}$ in the year 1852 but it took several decades for it to reach much use. The basic concept of sputter deposition is based on momentum transfer. In analogy with a game of pool, a high energy incident particle will hit the surface of any desired material, ejecting the source or "target" atoms (figure 1). The ejected particles will be transported through the deposition chamber and eventually condense on the substrate. What makes sputtering attractive for research and industry is that the synthesis procedure is usually done far from thermodynamic equilibrium, allowing synthesis of metastable material.

The sputtering yield for a specific working gas is defined as the number of ejected target atoms per incident particle (normally a noble gas ion) which is usually between 0.1 and 3 . The sputtering yield is related to the energy and incident angle of the bombarding ions, the relative masses of the ions and target atoms, ambient pressure, and the surface binding energy of the target atoms ${ }^{42} 43$. 


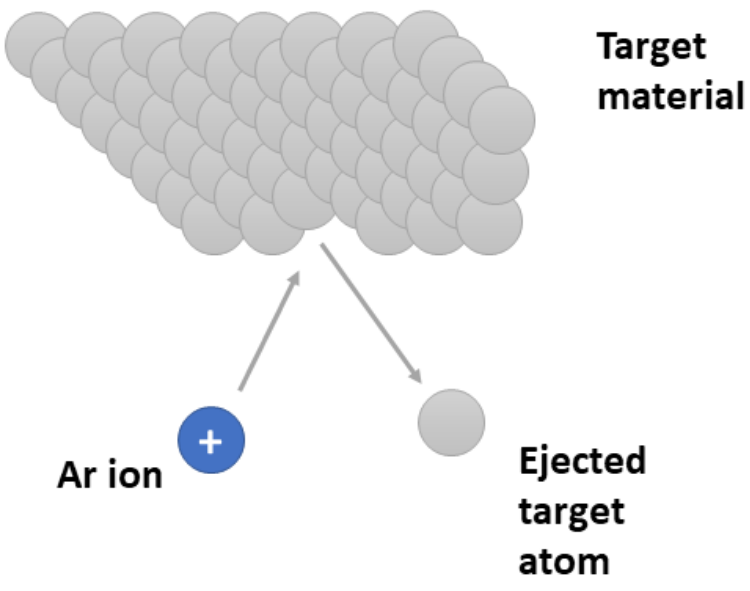

Figure 1. Incident ions will collide with the target material and eject the surface atoms. Particle energy and mass, incident angle, and ambient pressure all play key roles in how the target surface will be affected.

For sputter deposition, a vacuum chamber is required (figure 2). The created vacuum is needed to remove any residual gases, especially water vapor, which can deterioration the synthesis process by oxidization. The maximum vacuum attainable by the system is known as the base pressure. However, sputtering requires a steady flow of the sputtering gas, which will amount to a constant working gas pressure. A too low working gas pressure will prevent the plasma from igniting. A too high working gas pressures will result in more target material to be sputtered for the deposition, but will also thermalize the sputtered species, losing their energy. As the distance between the target and substrate is kept at a constant, thermalized particles will go through a random walk process and the mean free path will be small, hindering nucleation at the surface. Particles in a working gas pressure of 4.5 mTorr will have a mean free path of approximately 1 $\mathrm{cm}^{44}$

A noble inert gas is used as the sputtering gas. As momentum transfer is most efficient when the mass of the target atoms and the working gas are similar, argon gas is used for most targets as it is cheap, abundant and suitable for most materials, 
although a gas mixture with neon (for light element sputtering) or krypton (for heavy element sputtering) could be used.

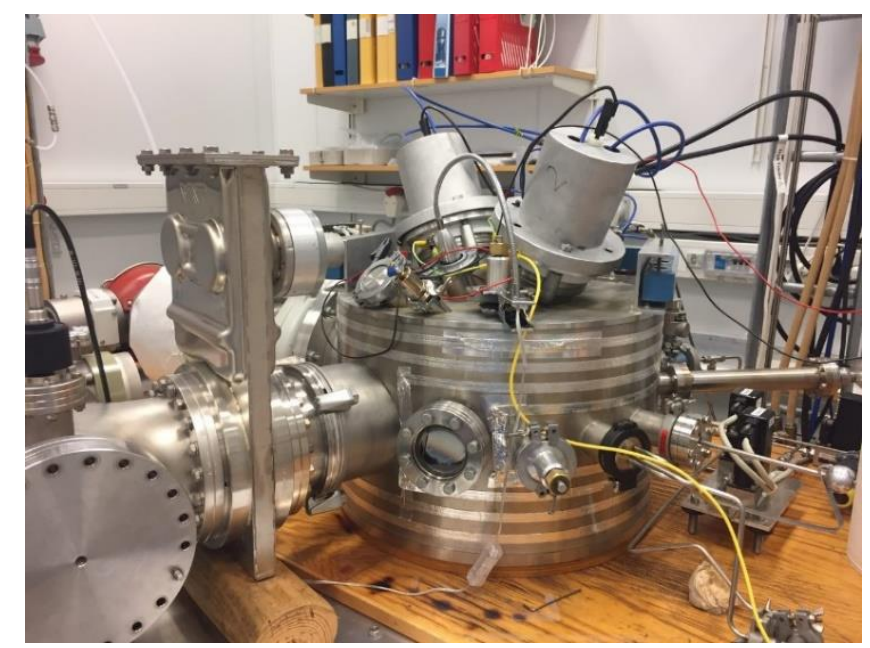

Figure 2. High vacuum DC magnetron sputtering chamber "Adam". Base pressure is $2 \times 10^{-7}$ $\mathrm{mBar}$. A base pressure at this level would have an approximate particle mean free path of $250 \mathrm{~m}$. Note the installation of two magnetrons (plus computer-controlled shutters) utilizing two separate targets. Photo by the author.

In order to ionize the argon gas and guide the ions towards the target, an electric field is utilized with the target material acting as the negative terminal (the cathode) and the chamber walls acting as the positive terminal (the anode). A stray free electron is accelerated by the electric field from the cathode towards the anode. When the electron reaches the first ionization energy of argon $(15.7 \mathrm{eV})$, a direct hit with an argon atom will ionize the atom and eject another electron:

$e^{-}+A r \rightarrow A r^{+}+2 e^{-}$

Eventually, the result will be an avalanche of electrons constantly ionizing argon gas which themselves will start to feel the electric field and be attracted towards the cathode. The outcome of a direct impact with the target surface will be sputtered atoms and secondary electrons. The sputtered atoms will travel to the substrate and if the distance between the target and substrate and the mean free 
path of the atoms are optimized, a thin film will deposit on the substrate. On the other hand, the secondary electrons will again enter an "avalanche" process to continuously form positive argon ions. The discussed mechanism is known as diode sputter deposition which utilizes an electric field and a self-sustaining plasma (a mixture of positive ions, electrons, and neutral atoms) for the deposition process. The self-sustainability of the plasma can be visually confirmed by the plasma glow which is the result of the recombination of an argon ion with an electron and emitting visible light (figure 3).

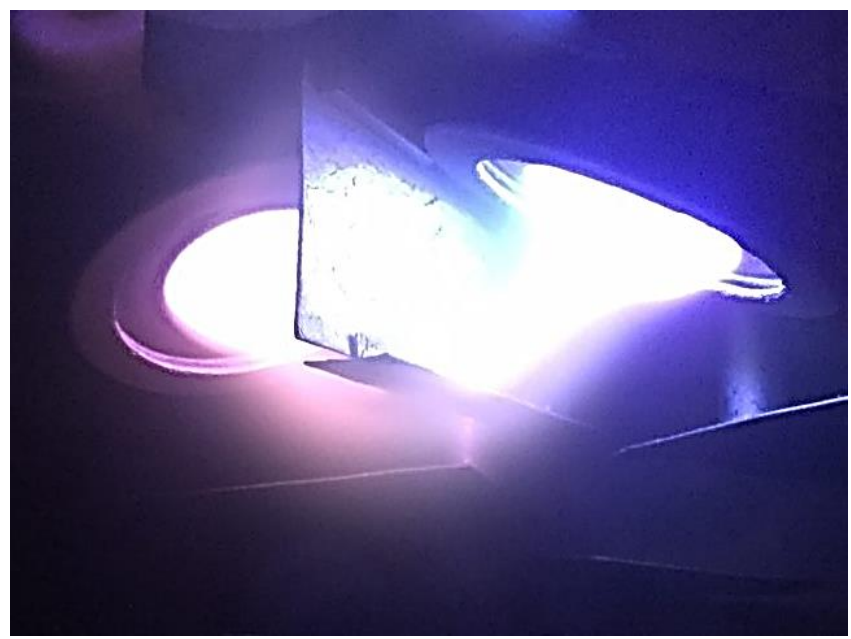

Figure 3. Pure argon plasma glow from the HV dual magnetron sputtering system "Adam". Photo by the author.

Today, diode sputtering is generally considered obsolete (however, it is sometimes used for sputtering targets with magnetic properties). A high working pressure of 100 mTorr is needed for the plasma to remain self-sustaining (as the probability of an impact between the electron and the argon atom is low) and these gas pressures greatly decrease the mean free path of the ejected atoms resulting in a very slow deposition rate with a low film uniformity. The utilization of a magnetron will allow lower working pressures (approximately 1-10 mTorr) while self-sustaining the plasma. 


\section{Magnetron sputtering}

The magnetron consists of two or more permanent magnets stationed behind the target with opposite poles sided next to each other and water-cooled to ensure that their temperature will remain below the Curie temperature ${ }^{45}$ and their melting point. The generated magnetic field will trap the secondary electrons forcing them to move in a helical motion along the field lines, increasing the electronic mean free path near the target (and ionization process of the working gas) before being absorbed and allowing lesser working pressures for the deposition process. The physics behind this phenomenon can be described by the Lorentz force:

$$
\boldsymbol{F}=q_{e}(\boldsymbol{E}+\boldsymbol{v} \times \boldsymbol{B})=m_{e} \boldsymbol{a}
$$

The electric and magnetic fields will cause a helical motion (figure 4).

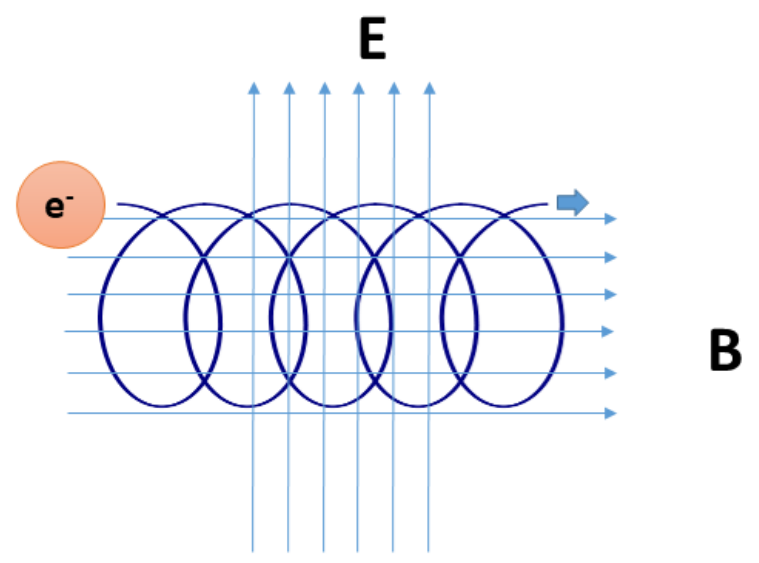

Figure 4. The "right hand law" will force the electron to move in circles in the presence of a magnetic field. The spiral movement will increase the mean free path of the electrons.

A sputtering system that includes a magnetron is known as a magnetron sputtering system (figure 5). The disadvantage of a magnetron sputtering system is that only a fraction of the target that is located in between the magnets is sputtered (the target "race-track"). 
Methods have been devised to reduce waste. Target providers usually accept and recycle expensive metallic targets for a lower resale price and industrial scale sputtering systems incorporate revolving cylindrical or very large rectangular targets with an optimized magnet configuration for maximum target utilization.
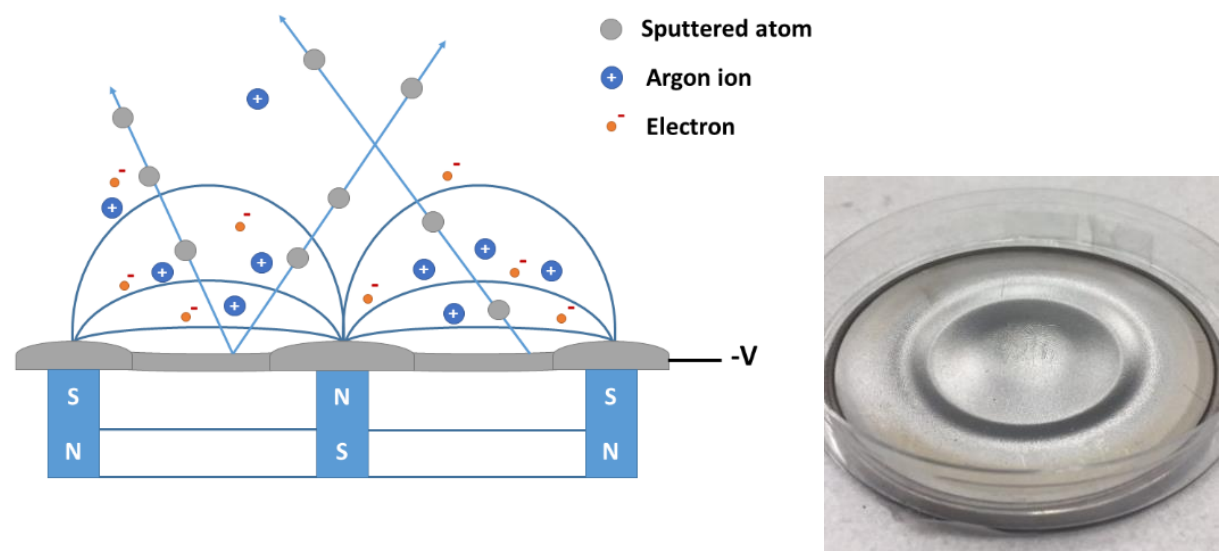

Figure 5. Schematic diagram of a target installed above a magnetron. Magnetron sputtering has the disadvantage of etching only a fraction of the target material known as the "race-track". Photo by the author.

The strength of the magnetic fields of the inner and outer magnets can either be equal (balanced) or non-equal (unbalanced) which is shown in figure 6. Balanced magnetrons fully confine the plasma near the target surface and are used when low-yield sputtering and low ion-bombardment of the film is desired. The unbalanced configuration includes type-I and type-II designs, where either the magnetic flux of the center pole is greater than the outer poles (type-I) or the magnetic flux of the outer poles is greater than the center pole (type-II). It is the type-II configuration in which the magnetic field lines deviate from the magnetron and cover a large area. This will lead the plasma to extend and include the substrate. The argon ions will affect the growth of the thin film and can enhance the film quality. Substrate bias is also used in order to utilize argon ions for the growth process as a negative bias will attract argon ions towards the growing film. One can regulate the bias voltage and use this mechanism to ion etch and clean the 
substrate and remove physisorbed contaminants or to influence the growing film (adhesion, nucleation, crystal structure, and texture) by choosing an appropriate bias and form different film qualities ranging from highly defective polycrystalline films with small grain sizes to highly textured large grained films. If the bias of the substrate is positive, electron heating occurs, but typically in a non-uniform and uncontrollable fashion.

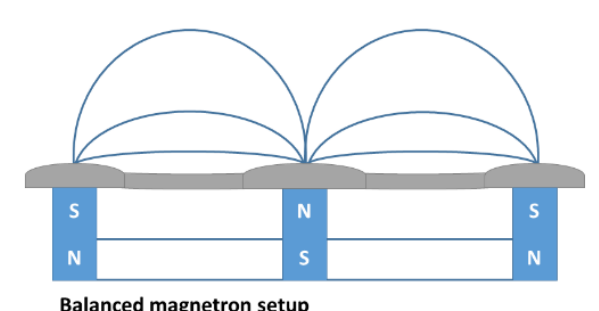

Balanced magnetron setup

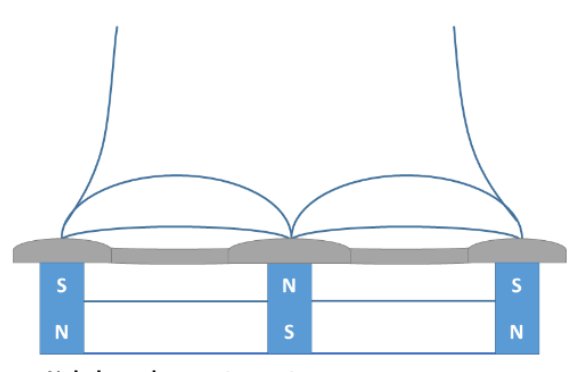

Unbalanced magnetron setup

Figure 6. Magnetrons in the balanced (left) and unbalanced type-II (right) configuration.

The sticking coefficient is temperature dependent. Too low temperatures will hinder surface diffusion and adatom mobility, which will disrupt the layer formation. On the other hand, too high temperatures will result in re-evaporation of different atoms. Decreasing the substrate temperature will allow deposition on temperature sensitive substrates and will also decrease the amount of energy required for the process.

Magnetron sputtering systems deposit different materials in both the form of pure elements and/or solid solutions. For alloys, one can sputter the desired material from an alloy target. However, the sputtering yield of the constituents of the alloy target can be an issue. As the sputtering yield for any given target atom is different, the constituents of the alloy target will sputter at different rates which may disrupt film stoichiometry. For example, in a hypothetical AB alloy system, element A may deplete as it has a higher sputtering yield while a surplus amount of element $B$ will remain. As time passes equilibrium will form (high sputtering yield for element A vs. higher concentrations for element B) and stoichiometry will be 
preserved leading to the conclusion that alloy sputtering is a self-sustaining process, if the target is conditioned initially before starting the deposition process.

For a compound target (oxide, nitride, etc.) the ejected particles are usually not of compound nature (metal oxide/nitride molecule). Also, the sticking coefficient of the electronegative element is likely to be lower, resulting in sub-stoichiometric films. ${ }^{46}$ Compounds may have very low sputtering yields which is why reactive sputtering is used instead.

\section{Reactive sputtering}

In reactive sputtering, a reactive gas is included in the gas flow to form nitrides and oxides (and carbides, oxynitrides, sulfides, etc.). The molecules/ions of the reactive gas will combine with sputter deposited atoms and form the compound material. However, the reactive gas may also react with the target material and "poison" the target by creating an oxide/nitride film with a new sputtering yield. The deposition process will continue with a poisoned target, but because the sputtering yield decreases, the film formation time on the substrate will increase, resulting in slowly deposited stoichiometric film. The surface layer may also increase surface resistivity and the target potential will drop. In order to solve this problem, the gas flow of the reactive gas must be regulated to obtain desired deposition rates and stoichiometry. ${ }^{47}$ Figure 7 represents a graph showing the hysteresis loop of the process. The reactive gas flow is increased to obtain desired stoichiometry, though at the critical point the target will become poisoned and the deposition rate will drop instantly. 


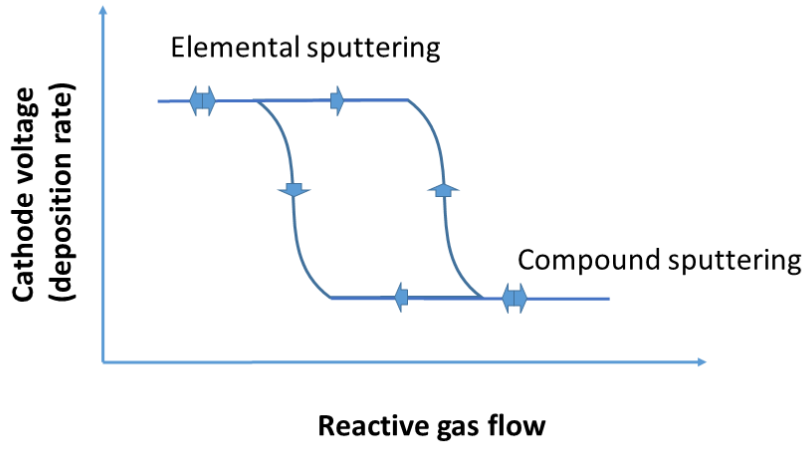

Figure 7. The hysteresis loop for reactive sputtering. Note that the transition from metal target and compound target takes place at two different gas flows.

Decreasing the gas flow will not instantly exit the system from poisoned state as it takes time for the reactive gas to desorb from the chamber walls. An automated feedback loop can be used to maintain the reactive gas flow in the transition region between poisoned mode and elemental sputtering.

\section{RF sputtering}

Another issue regarding sputtering is depositing electrically insulating materials. As the deposition proceeds and target atoms are ejected, secondary electrons will form, leaving behind a positive charge on the target. The accumulation of these charges will disrupt the argon plasma by repelling the positive ions, decreasing secondary electron formation and eventually extinguishing the plasma. Also, for the target to work at appreciable currents, very high potentials $\left(10^{12} \mathrm{~V}\right)$ are required, which is not practical. In this case, we can use radio frequency magnetron sputtering, which utilizes a radio-frequency AC power supply instead of a DC one. The effective resistance of dielectrics can be varied with the frequency of the electric current and reasonable voltages can sustain the electric current by seeing a lower impedance. With the anode and cathode switching signs at a frequency of 13.56 MHz, the charge build-up will be neutralized (self-biasing) with the electrons 
preventing the disruption of the plasma. The heavier ions cannot follow the switching and because the chamber and substrate are very large, they will not be sputtered in negative bias. One should note, however, that these power sources are more complex (and expensive) and because only half the time the target is in negative bias, deposition rates decrease. ${ }^{48}$ 


\section{The microstructural evolution of thin films}

The microstructure features of a thin film govern many of the electronic, optical and mechanical properties. These features include uniformity, grain size, texture, thickness, etc. Therefore, there is a need for understanding and control of the microstructural evolution of thin films.

\section{Epitaxial growth}

Polycrystalline thin films have multiple applications especially as protective coatings for their desired chemical inertness and/or superior mechanical properties, but electronic and optoelectronic devices require epitaxial thin films. This term was first coined in 1928 by Royer ${ }^{49}$ which is derived from the Greek words epi (̇ं $\tilde{i})$, meaning "above", and taxis ( $\tau \dot{\alpha} \xi 1 \varsigma)$, meaning "an ordered manner". Depositing a thin film on a monocrystalline substrate requires the lattice of the film and substrate to match each other with the least lattice mismatch possible. If coherent heteroepitaxial growth is desired, strain will ultimately be present, but a small lattice mismatch can be afforded. The strain will increase with film thickness. By the following equations, on can calculate both the lattice mismatch $(\epsilon)$ and critical thickness $\left(d_{c}\right)$ of the film in which the film will be strained but without any major defects:

$\epsilon=\left(a_{S}-a_{L}\right) / a_{L}$

$d_{c} \approx a_{S} /(2|\epsilon|)$

where $a_{S}$ is the lattice parameter of the substrate and $a_{L}$ is the lattice parameter of the deposited layer.

In the case where the film thickness exceeds the critical limit (which usually is the case), relaxation will occur at the film/substrate interface by the introduction of misfit dislocations. One alternative solution would be to deposit films of a seed layer on the substrate. The seed layer should have a low mismatch with the thin film to ensure that the relaxation will be confined to the interface with the substrate. 
Thus, the lattice mismatch controls the self-assembly deposition process, which is categorized into three different growth mechanisms (figure 8):

The Volmer-Weber process: Surface tension is high, adatom-adatom bonding is preferred, and island growth is distributed across the substrate surface. The high lattice mismatch and surface roughness of such films initially make this growth process undesirable for epitaxial films. However, this process can be very valuable for the synthesis of self-organized zero-dimensional quantum dots used for optoelectronics $^{50}$.

The Frank-van der Merwe process: Adatoms tend to bond with the substrate instead of each other and the stress from lattice mismatch is low, resulting in a layer by layer growth process of smooth films $\mathrm{s}^{5152}$.

The Stranski-Krastanov process: When surface tension and lattice mismatch is in between the two previous situations, the film will grow in a layer by layer fashion until reaching the critical thickness. At this point, the reduction of strain energy will result in island growth. A growth process like this will result in polycrystalline films if the film thickness exceeds the critical limit ${ }^{54}$. This growth mode is also used for self-organized quantum dot synthesis.
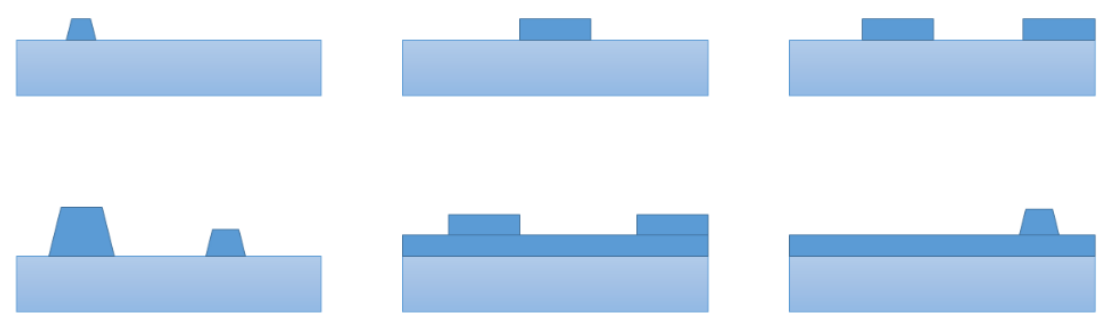

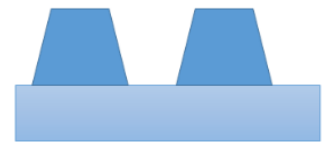

Volmer-Weber

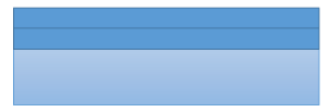

Frank van der Merwe

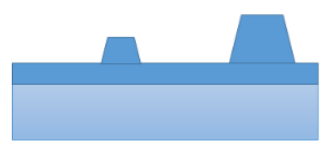

Stranski-Krastanov

Figure 8. Thin film self-assembly growth mechanisms. Depending on the extent of the lattice mismatch between the film and the substrate, the film would follow one of the three processes. 


\section{Polycrystalline Thin Films}

The deposited film will arrange itself in a way to obtain maximum stability and therefore minimum energy. Thus, structural evolution is determined by the minimization of the Gibbs free energy:

$G=G_{0}+\sum A_{i} \gamma_{i}+\sum G_{S j}$

where $A_{i}$ is the area of the interface, $\gamma_{i}$ is the excess free energy of the interface and, $G_{S j}$ is the energy stored in the strain-inducing defects. $G_{0}$ is the minimum Gibbs free energy of a perfect bulk crystal which is a constant. $A_{i} \gamma_{i}$ represents the excess free energy of a crystallite which stems from grain boundaries (GB), filmsubstrate interface and film free surface. As a result, the reduction of $\sum A_{i} \gamma_{i}$ will determine the outcome of the preferred orientation and grain size. Also, various defects present in the film like impurity atoms, vacancies, dislocations, stacking faults, etc. will induce strain inside the film. In order to minimize $\sum G_{S j}$, the growth process will go towards strain reduction which affects preferred orientation. In cases where the strain propagates into the film structure, film texture as a function of film thickness is seen.

\section{Formation kinetics}

The deposition initially starts by the formation of stable nuclei that come from impinging atoms on the substrate surface which consequently leads to stable clusters. The nucleation rate is directly dependent on the deposition rate and substrate temperature. In the case of sputtering, the deposition rate depends on the working gas pressure, the target material sputtering yield, and the energy of the impinging ions. At this point a competition between various factors emerge. Too high substrate temperatures may cause the adatoms to re-evaporate from the substrate while too low temperatures will decrease surface mobility of the adatoms. The ratio of the substrate temperature over the melting temperature of the deposited material (known as the homologous temperature, $T_{s} / T_{m}$ ) governs surface diffusion and atom mobility. In case of high enough mobility, the atoms tend to nucleate around surface defects and form crystallites with a selected 
orientation to enhance stability. Low mobility will result in fine grains or amorphous structures with a high degree of shadowing effects. In order to increase mobility without increasing the temperature, a negative substrate bias is a method of choice in sputtering. The incoming argon ions provide sufficient energy for grain boundary migration, coalescence, and layer densification. However, too high energies will result in structural defects inside the film, re-sputtering and ion implantation, and the incorporation of gas pockets.

As the atoms accumulate to form larger and larger nuclei, islands take shape. Each island has its own unique growth rate and preferred orientation which stems from minimizing the Gibbs free energy. When the islands grow large enough, they come into contact (island coalescence). Depending on the diffusivity and mobility of the atoms, these islands may remain separated via grain boundaries or some larger islands grow by absorbing smaller neighboring islands. In low temperature depositions when there is a small contribution from ion irradiation, the grains tend to be small with no GB migration. The resulting films will turn porous and polycrystalline (or even amorphous). The absence of surface diffusion and atom mobility prevents the system from overcoming the activation barrier and the resulting structures will remain in a metastable state.

In the case of high surface diffusion and atom mobility, the island coalescence comes to the point in which more energetically favorable islands will grow at the expense of more unstable ones. In this case, GB migration and bulk diffusion have a pronounced effect, and recrystallization occurs. Also, the GB interface energies decrease as grain coarsening decreases the number of grain boundaries. Islands with a denser set of planes are more favored; (111) planes for fcc structures, (110) for bcc, and (0002) for hcp structures. ${ }^{55}$

In addition to the film deposition process, post growth annealing of the films can also play a role in altering the microstructure by providing enough energy for additional GB motion and bulk diffusion leading to a textured film composed of large crystallites with smooth surfaces.

After a continuous film is developed, film thickening can proceed in different directions. In case of low mobility situations, incoming atoms will re-nucleate on the previous grains and atomic shadowing will result in a fibrous film with a high degree of porosity. A structure like this is also favored when defects and impurities are present, hindering surface diffusion. In the case of suitable surface diffusion 
and mobility, localized epitaxial growth will ensure that arriving atoms will continue the crystallite growth resulting in large columnar grains with preferred orientation and smooth surfaces. Deposition rates also play a role in determining the microstructure. Too low deposition rates will result in an increase in the impurity inclusion in the film (preventing GB motion, atom mobility and introducing defects) while too high deposition rates will decrease the required time for atoms to position themselves for surface diffusion and local epitaxy. The atoms will be "buried" under new incoming atoms and the film will turn porous.

At this point, a quantitative standard that will relate the main deposition parameters with the microstructure of the film can be of great importance. Movchan and Demchishin ${ }^{56}$ were the first to propose a Structure Zone Model (SZM) guideline which relates microstructural features to the $T_{s} / T_{m}$ ratio (substrate temperature over melting temperature, see figure 9). Other prominent growth parameters like gas pressure effects and substrate bias were also taken into account by Thornton ${ }^{57}$ ${ }^{58}$ and Messier et al. ${ }^{59}$ in later Structure Zone Models.

It is shown that at low $T_{s} / T_{m}$, the film will have a fibrous structure, composed of small crystallites or fully amorphous structures. The incoming atoms do not have enough kinetic energy to overcome the activation barrier for atom mobility and surface diffusion. This will result in atomic shadowing, structural defects, and porosity and the film will be known as a "zone I" structure.

In case of increased $T_{s} / T_{m}$ or with the help of ion irradiation (in which momentum transport from incoming positive ions to the surface atoms occur), the film will enter the "transition zone". The adatoms will now have enough energy for surface diffusion and GB motion. Zone $\mathrm{T}$ thin films are composed mainly of various crystallites with their respective crystal orientation engaged in competitive growth. Crystal planes with lower free energy will prevail and continue to form thin columnar grains with rough surfaces.

"Zone II" structures form when bulk diffusion is high. At this point liquid like coalescence is seen and grain coarsening occurs with and after island coalescence resulting in a highly textured film composed of large columnar grains. 


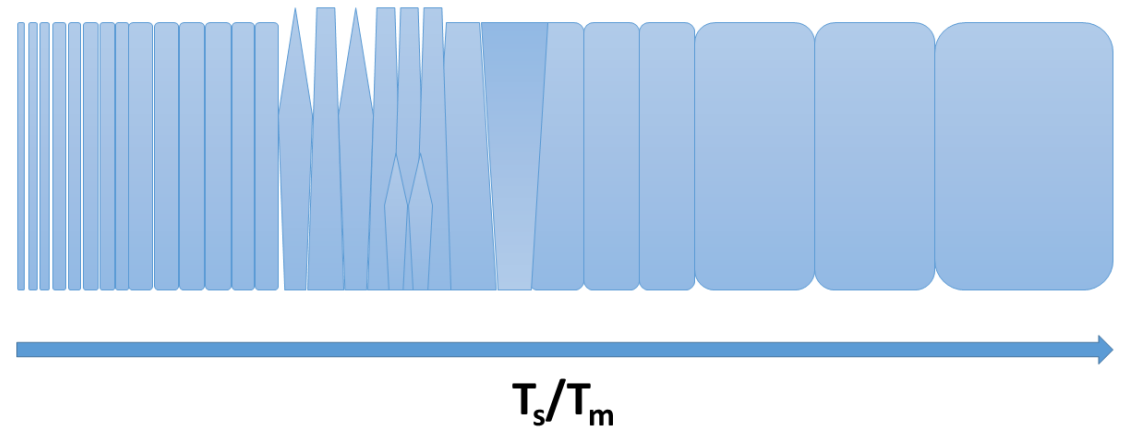

Figure 9. Structure zone models for thin films. As the $T_{s} / T_{m}$ ratio increases, enhanced adatom mobility transforms the fibrous and porous film into a dense film composed of large crystal grains. Drawn based on an original from P. B. Barna and M. Adamik. ${ }^{60}$ 


\section{Thermoelectrics: basics and challenges}

The Seebeck effect, which was discovered in the early 1800s, has the potential to provide more efficient energy cycles. Internal combustion engines and industrial facilities produce large amounts of waste heat which can be recycled to decrease fuel consumption. This is done by directly transforming a temperature gradient into an electrical current, a process used in deep-space exploration which requires reliable and long-lasting power generators. Other applications include wearable electronics, high-temperature sensors or power for remote lighting/sensors were wiring is deemed a liability. The opposite of the Seebeck coefficient, the Peltier effect, is used in some consumer applications and has also drawn interest for its prospective role in providing a reliable and compact heat spot cooling method for high-tech electronic and optoelectronic devices without the need for a coolant or any moving parts.

Although the proposed applications seem promising, progress in the development of effective thermoelectric devices has been rather slow. This is mainly due to the limitations on their efficiency, expressed through the dimensionless figure of merit $z T^{61}$ :

$z T=\frac{\alpha^{2} \sigma}{\kappa} T$

where $\sigma=1 / \rho$ is the electrical conductivity, $\alpha$ is the Seebeck coefficient ${ }^{\dagger}, T$ is the absolute temperature and $\kappa$ is the thermal conductivity of the material. The product $\alpha^{2} \sigma$ is known as the power-factor. Note that the quantity " $z T$ " is preferred over " $z$ ". The reason is that $\frac{\alpha^{2} \sigma}{\kappa}$ changes with temperature. Thus, there is a need for thermoelectric materials for different temperature regimes. This equation is used to evaluate the performance of a thermoelectric device. If $z T$ reaches infinity, the efficiency of the thermoelectric device will reach the theoretical maximum of a Carnot heat engine, but typically the $z T$ of modern thermoelectric devices are close to unity. Unfortunately, the parameters $\alpha, \sigma$ and $\kappa$, do not change

\footnotetext{
'The letter " $\mathrm{s}$ " is also used to denote the Seebeck coefficient, but it will be avoided in order to prevent confusion with "S", i.e., entropy.
} 
independently under ordinary circumstances because of their interdependence with each other. As a result, the main goal of a materials scientist would be to maximize the power factor of a thermoelectric device and minimize its thermal conductivity.

\section{Basics}

If one side of a thermoelectric device is heated and the other side is kept at a fixed low temperature, an electric current can be measured (figure 10, left image).

The opposite is also true: if an electric current is passed through a thermoelectric device, one side will heat up while the other side will start to cool. This is known as the Peltier effect (figure 10, right image).
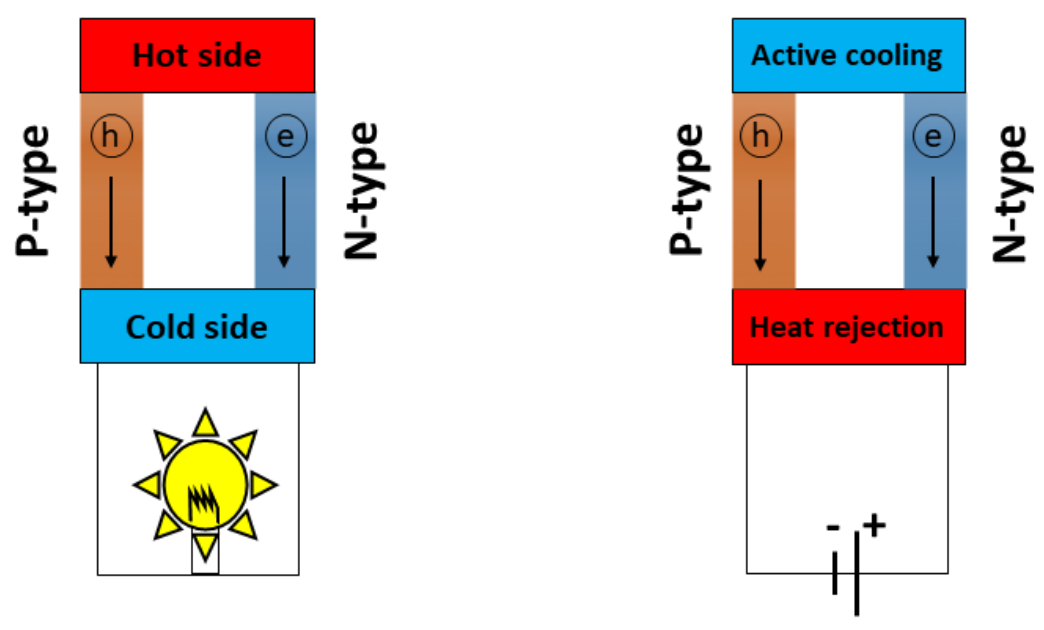

Figure 10. Schematic illustration of a thermoelectric couple in power generation (left) and solidstate refrigeration (right).

The cause is the thermoelectric effect which occurs when a temperature gradient is established over a conducting or semiconducting material (figure 11). When 
thermal energy is introduced, the low energy charge carriers migrate from the hot side of the material to the cold side, causing an electric field inside the material.

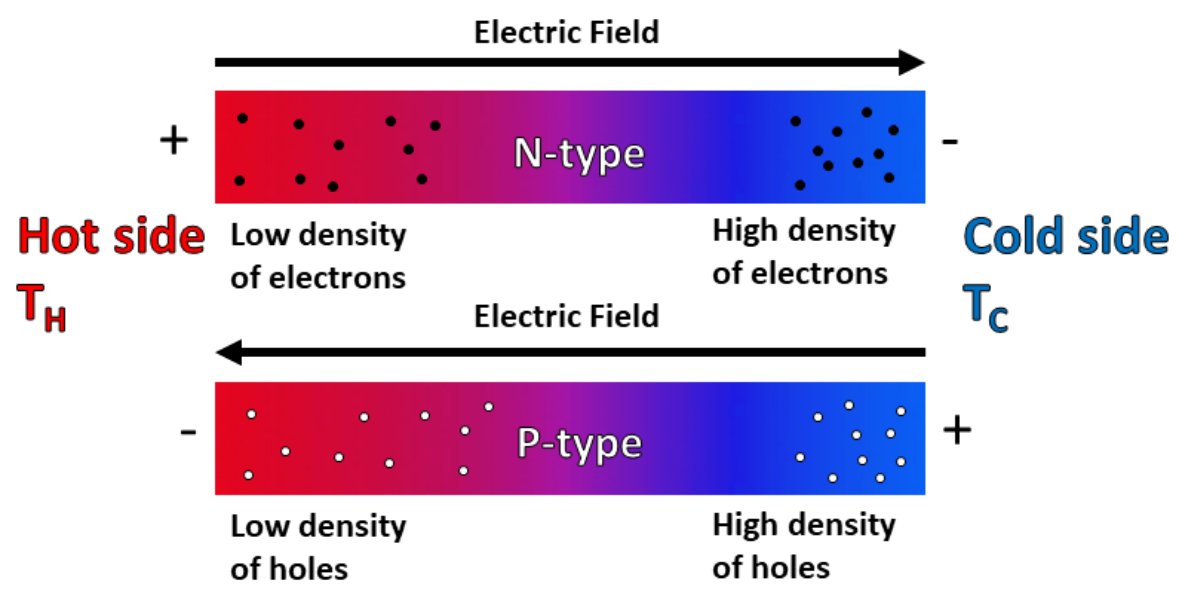

Figure 11. When a thermal gradient is established, the more energetic charge carriers (electrons and holes) with larger mean free paths migrate towards the cold side of the thermoelectric junction until a stopping electric field is established.

There are a couple of issues that one must consider regarding thermoelectrics. Although the classical $z T$ equation gives a good idea of whether a thermoelectric material has the desired properties, other parameters like device efficiency must also be considered. First, thermoelectric devices work with material pairs. Using material with the same charge carrier nature will cancel the current, as a result ntype and p-type semiconductors are used. A more applicable equation regarding semiconductor couples is:

$$
z T=\frac{\left(\alpha_{p}-\alpha_{n}\right)^{2} T}{\left[\left(\rho_{n} \kappa_{n}\right)^{1 / 2}+\left(\rho_{p} \kappa_{p}\right)^{1 / 2}\right]^{2}}
$$


The $\mathrm{p}$ and $\mathrm{n}$ indices represent $\mathrm{n}$-type and $\mathrm{p}$-type semiconductors, which will form the thermoelectric couple. Note that metals have high thermal conductivity and very low Seebeck coefficient values and insulators (like glass) have almost no electrical conductivity, thus the power factor and the figure of merit of these materials render them useless for thermoelectric devices unless used in combination with semiconducting material.

If one plans to obtain the efficiency of the device, the equation would be:

$\eta_{T E}=\frac{W}{Q_{H}}=\frac{T_{H}-T_{C}}{T_{H}}\left(\frac{\left(1+z T_{M}\right)^{1 / 2}-1}{\left(1+z T_{M}\right)^{1 / 2}+{ }^{T} C / T_{H}}\right)$

where $T_{M}$ is the mean temperature of the device. Based on the above equation and its relation to the Carnot engine efficiency, at operating temperatures between 300 and $800 \mathrm{~K}$ and a $z T$ of 3 , one can expect efficiencies of above $40 \%$ of the Carnot efficiency if such $z T$ values could be achieved.

However, as mentioned previously, " $z$ " changes with temperature. Thus, an engineering ${ }^{62}$ figure of merit and efficiency equation is required for accurate calculations:

$$
\begin{aligned}
& (z T)_{\text {eng }}=z_{\text {eng }} \Delta T=\frac{\left(\int_{T_{C}}^{T_{h}} \alpha(T) d T\right)^{2}}{\int_{T_{C}}^{T_{h}} \rho(T) d T \int_{T_{C}}^{T_{h}} \kappa(T) d T} \Delta T=\frac{(P F)_{e n g}}{\int_{T_{C}}^{T_{h}} \kappa(T) d T} \Delta T \\
& \eta_{T E}=\eta_{c} \frac{\sqrt{1+(z T)_{\text {eng }}\left(\hat{f} / \eta_{C}-\frac{1}{2}\right)}-1}{\hat{f}\left(\sqrt{1+(z T)_{e n g}\left(\hat{f} / \eta_{C}-\frac{1}{2}\right)+1}\right)-\eta_{c}}
\end{aligned}
$$

where $\eta_{c}$ is the Carnot engine efficiency and $\hat{f}$ is the dimensionless intensity factor of the Thomson effect ${ }^{\ddagger}$ :

\footnotetext{
${ }^{\ddagger}$ Also known as the homogeneous thermoelectric effect. When an electric current is conducted through a material under a temperature gradient, the material in question will start to absorb or expel heat along the temperature gradient depending on electric current direction and material properties (positive Thompson vs. negative Thompson).
} 
$\hat{f}=\alpha\left(T_{h}\right) \Delta T / \int_{T_{c}}^{T_{h}} \alpha(T) d T$

When the Seebeck coefficient is independent of temperature, $\hat{f}=1$. In addition, the output power density $\left(\mathrm{W} \mathrm{m}^{-2}\right)$ at the maximum efficiency, $P_{d}$ is:

$P_{d}=\frac{(P F)_{e n g} \Delta T}{L} \frac{m_{o p t}}{\left(1+m_{o p t}\right)^{2}}$

where $L$ is the length of a cubic TE leg and $m_{\text {opt }}$ is the optimized ratio of external electric load $R_{L}$ and internal resistance $R . P_{d}$ is of interest as it is directly connected to the power-factor.

Although, the traditional $z T$ and efficiency equations are still relevant as an easy reference for evaluating TE material, for accurate prediction of device output the engineering equations are needed. For example, Kim et al. (reference 62) has shown that there is a factor of 2 over-estimation in efficiency for tin selenide ( $\mathrm{SnSe}$ ) measurements when using the classical equation in comparison to the $17 \%$ over-estimation when using the engineering ones. Please note that equations 9 and 10 do not consider the Thomson effect on the heat flux evaluation, but rather is the relative degree of the Thomson effect contribution to an analytically predicted efficiency. More accurate (and complicated) equations including contributions from Thomson and Joule heat to the heat flux will obviously result in more accurate calculations and predictions.

\section{The Seebeck coefficient}

Measuring the Seebeck coefficient can be done by a simple П-configuration setup. Figure 12 shows a TE device based on two thermoelectric films acting as the ntype and p-type leg. 


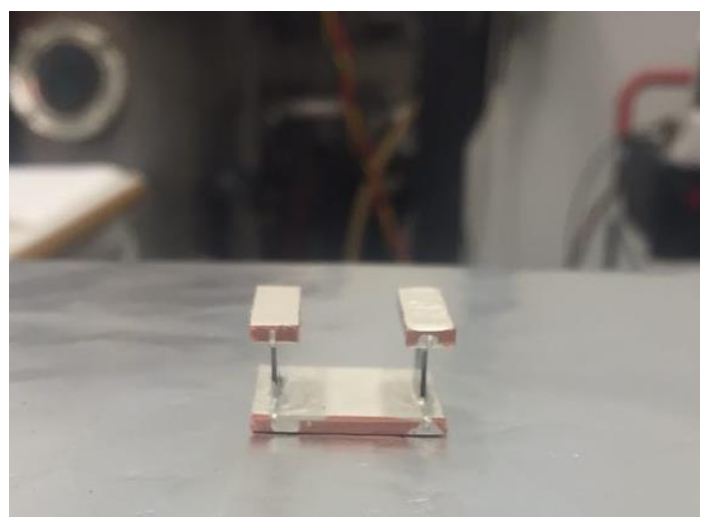

Figure 12. A thermoelectric generator (TEG) in the П-configuration. The TEG is placed on a hot plate which will allow temperature dependent Seebeck coefficient measurements.

A $\mathrm{CrN}$ thin film is used as the n-type leg and a $\mathrm{Ca}_{3} \mathrm{Co}_{4} \mathrm{O}_{9}$ thin film as the p-type leg. ${ }^{63}$ For the thermoelectric couple measurements, a $2.4 \mathrm{~cm}$ by $2.4 \mathrm{~cm}$ stainless steel plate with two parallel grooves were used to vertically hold the thin film substrates. This plate was used as the hot side of the device and was laid upon a $300{ }^{\circ} \mathrm{C}$ hotplate. Two smaller $2.4 \mathrm{~cm}$ by $0.5 \mathrm{~cm}$ plates were used for each leg acting as both the device heat sink and as contacts for electric potential measurements. A thermocouple connected to a multi-meter is used to measure the temperature difference between the heat source $\left(300{ }^{\circ} \mathrm{C}\right)$ and the heat sink $\left(200{ }^{\circ} \mathrm{C}\right)$ of the thermoelectric generator. The n-type leg voltage absolute value is measured to be $21.5 \mathrm{mV}$ and the $\mathrm{p}$-type leg voltage absolute value is measured to be $16.0 \mathrm{mV}$. The $\mathrm{S}=-\Delta \mathrm{V} / \Delta \mathrm{T}$ equation can be used to estimate the Seebeck coefficient of each leg, and as the temperature difference between the heat source and heat sink is approximately $100^{\circ} \mathrm{C}$, the Seebeck coefficient of $\mathrm{CrN}$ is estimated to be $215 \mu \mathrm{V} / \mathrm{K}$ and the Seebeck coefficient of $\mathrm{Ca}_{3} \mathrm{Co}_{4} \mathrm{O}_{9}$ is estimated to be $160 \mu \mathrm{V} / \mathrm{K}$. It is important to point out that if $\mathrm{CrN}$ is an n-type semiconductor and $\mathrm{Ca}_{3} \mathrm{Co}_{4} \mathrm{O}_{9}$ is a ptype semiconductor, then the open circuit voltage of the device should be the summation of both legs. Thus, this setup can also be used for identification of the charge carrier type of an unknown sample, if the setup also includes a known reference sample.

For fast and accurate room-temperature analysis of the Seebeck coefficient, an inhouse setup ${ }^{64}$ was used. Measurements were conducted in open-air conditions and 
the temperature gradient over the sample was approximately $50{ }^{\circ} \mathrm{C}$, from room temperature up to $74{ }^{\circ} \mathrm{C}$.

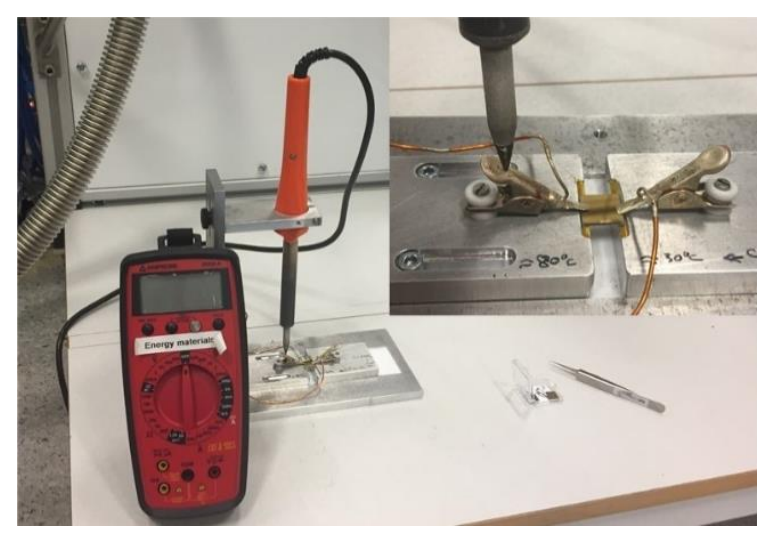

Figure 13. In-house built Seebeck setup used for room-temperature measurements.

Typical thermoelectric materials are narrow band-gap semiconductors, for increased electrical conductivity. High electron mobility is also required $(\mu \approx$ $\left.2,000 \mathrm{~cm}^{2}(\mathrm{~V} \cdot \mathrm{s})^{-1}\right)$, but the carrier concentration should be comparatively low so that both the electrical conductivity and the Seebeck coefficient can be addressed. The following equation explains the relationship between carrier concentration and the Seebeck coefficient:

$\alpha=\frac{8 \pi^{2} k_{B}^{2}}{3 e h^{2}} m^{*} T\left(\frac{\pi}{3 n}\right)^{2 / 3}$

A concentration between $10^{19}$ and $10^{20}$ carriers per $\mathrm{cm}^{3}$ is considered as an appropriate amount ${ }^{65}$ which is material dependent. The previous equation also shows that the carrier effective mass has a profound effect on the Seebeck coefficient. The $m^{*}$ refers to the density-of-states effective mass, which increases with a large slope of the density of states at the Fermi surface, increasing the Seebeck coefficient. However, a large effective mass will also decrease electron mobility and consequently, the electrical conductivity. It can be clearly seen that semiconductors with the required thermoelectric properties must be carefully selected, tailored and optimized to reach desired performance. 
If the operating temperature of the device is increased, larger band gaps are needed for thermal conductivity control. High temperatures also cause diffusion, chemical reactions and contact impairment which can seriously deteriorate the properties of the device. And as the maximum $z T$ value changes with temperature, no one thermoelectric material can be used for all applications and thermoelectric materials for different temperature ranges are required. Traditionally, bismuth telluride $\left(\mathrm{Bi}_{2} \mathrm{Te}_{3}\right)$ for low temperature, lead telluride $(\mathrm{PbTe})$ for mid-temperature and $\mathrm{Si} / \mathrm{Ge}$ alloys are used for high-temperature regimes. However, telluride based thermoelectrics are scarce, expensive and have thermal, chemical and mechanical stability issues ${ }^{66} 6768$. Si/Ge alloys used for long endurance applications (e.g., the Voyager space program) have excellent stability, but require very high $(\sim 1000$ ${ }^{\circ} \mathrm{C}$ ) temperatures fueled by expensive and scarce ${ }^{238}$ plutonium ${ }^{\S}$ or its oxide for optimal and safe usage. ${ }^{69} 70$ Other well-known radionuclides used as fuel are ${ }^{90} \mathrm{Sr}$, ${ }^{210} \mathrm{Po}$ and ${ }^{241} \mathrm{Am}$ which come with their own advantages and disadvantages.

\section{TE property optimization}

The focus on research regarding thermoelectric devices is mainly the development of semiconductor structures with optimum thermoelectric properties. For this to be achieved, one must increase the power factor and decrease the thermal conductivity of each of the semiconductor couples. The challenging aspect is that these two parameters do not change independently. In 1995 Slack $^{71}$ proposed an idea about what are the characteristics of a good thermoelectric material. He explained that thermoelectric semiconductors must have the electrical conductivity of a crystal and the thermal resistivity of glass. This is now known as the Phonon Glass-Electron Crystal approach (PGEC).

Thermal conductivity stems from charge carrier conduction and lattice vibrations (phonons). Charge carriers are required for high power factors; thus, research is

\footnotetext{
$\S$ The idea of plutonium production and usage may bother many as it is a reminder of nuclear weapons proliferation. However, ${ }^{238} \mathrm{Pu}$ is a non-fissile, relatively safe and easy to use isotope which requires minimum radiation shielding. ${ }^{238} \mathrm{Pu}$ has a half-life of 88 years and a very high decay heat of $560 \mathrm{~W} / \mathrm{Kg}$; ideal for high-temperature TE applications. Property wise, ${ }^{238} \mathrm{Pu}$ is a stark contrast of the toxic and highly dangerous weapons grade ${ }^{239} \mathrm{Pu}$.
} 
mainly focused on minimizing thermal conduction by phonon scattering. The total thermal conductivity is given by the following:

$\kappa=\kappa_{l}+\kappa_{e}$

$\kappa_{e}$ is the electronic contribution of thermal conductivity, and is naturally tied to the electrical conductivity by the Wiedemann-Franz law:

$\kappa_{e}=L_{0} \sigma T$

in which $L_{0}$ is the Lorentz number. This relationship and its dependence on the electrical conductivity $\sigma$ shows that not much can be done to decrease the electronic contribution of thermal conductivity as the power factor will also decrease.

On the other hand, $\kappa_{l}$ is:

$\kappa_{l}=\frac{1}{3}\left(v_{S} C_{V} L_{p h}\right)$

in which $v_{S}$ is the speed of sound, $C_{V}$ is the heat capacity at a constant volume and $L_{p h}$ is the mean free path of the phonons. Thus, the focus would be on the mean free path of the phonons and methods to decrease it to the point that it is essentially equal to the interatomic spacing of the constituent atoms. One such method would be alloying. This would cause short wavelength acoustic phonon scattering by introducing atomic sized point defects. An example would be the Si/Ge alloy used for high temperature radio isotope thermoelectric generators used by NASA. Both materials have a high thermal conductivity, but alloying results enhanced phononphonon and phonon-electron scattering. ${ }^{72}$

Complex inorganic crystals that include heavy metallic atoms also cause phonon scattering. If voids are created in the lattice structure which are partially or completely filled with heavy atoms, an effect known as rattling occurs which can also scatter phonons. ${ }^{73}$ These techniques are used to reduce the thermal conductivity below the alloy limit ${ }^{74}$ by scattering mid to long wavelength phonons. Quantum dots dispersed in a solid matrix can be formed in a variety of ways, including phase separation of an alloy during bulk crystal growth or by the Stranski-Krastanov or Volmer-Weber mechanisms during epitaxial growth. Research has shown that ErAs nanodots in an InGaAs/InGaAlAs matrix ${ }^{75}$ will 
cause effective scattering with the scattering cross section being proportional to $b^{6} / \lambda^{4}$, where $b$ is the size of the nanodot and $\lambda$ is the acoustic phonon wavelength (figure 13). When these rattlers and quantum dots are unevenly distributed or when the size varies, the scattering effects increase by reacting with a larger phonon spectra.

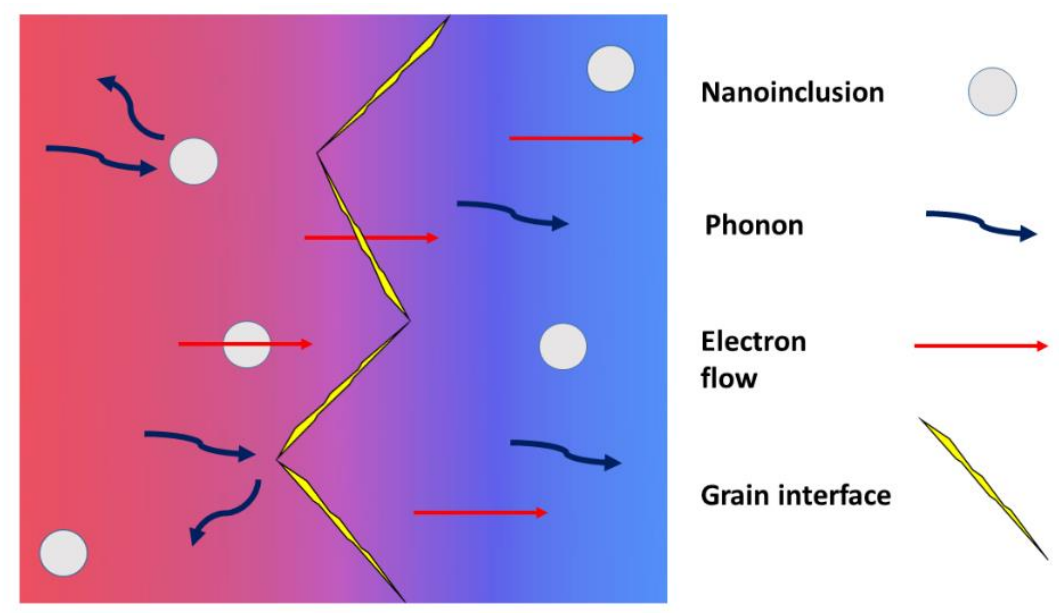

Figure 13. Schematic illustration of various phonon scattering mechanisms in action.

Another use of nanotechnology in the development of thermoelectric devices is the synthesis of superlattices to create charged-carrier confinement, phonon localization, specular scattering of phonons at interfaces due to acoustic mismatch and scattering of phonons at defects (dislocations from lattice mismatch) ${ }^{76} 77$. 78 . It has been shown that superlattice thin films with various/random thicknesses increase the scattering of phonons at the film interface. Cahill et al. presented multilayers that have a thermal conductivity comparable with air ${ }^{79}$ (approximately $0.03 \mathrm{Wm}^{-1} \mathrm{~K}^{-1}$ ). Nanocrystals, polycrystalline structures and highly disordered thin film crystal layers are also known to decrease the thermal conductivity. Jood et al. ${ }^{80}$ showed that microwave activated nanocrystals of Al-doped $\mathrm{ZnO}$ (and coldpressed into bulk pellets) has thermal conductivity values as low as $1.5 \mathrm{Wm}^{-1} \mathrm{~K}^{-1}$ which is a result of nanostructure-induced suppression of the thermal conductivity. Such procedures will result in a limited flow of hot electrons which will reduce 
electrical conductivity, but at high enough operating temperatures, it will mostly affect the thermal conductivity of the thermoelectric device and as a result, enhance $z T$.

Most modern approaches into maximizing $z T$ have been done by decreasing the lattice contribution of thermal conductivity. It seems that this specific approach does work well in improving current thermoelectric materials. However, researching unexpected material is an avenue to be explored. Semiconducting hard coatings like scandium nitride $(\mathrm{ScN})$ or chromium nitride $(\mathrm{CrN})$ show good thermal, chemical and mechanical properties at high temperatures. $\mathrm{ScN}$ is known to have high power factors ${ }^{81}$ (max: $3.3 \times 10^{-3} \mathrm{Wm}^{-1} \mathrm{~K}^{-2}$ at $800 \mathrm{~K}$ ) and $\mathrm{CrN}$ is known to have a Seebeck coefficient close to $-230 \mu \mathrm{V} / \mathrm{K}$ (discussed in paper I) and a thermal conductivity ${ }^{82}$ between 2 and $4 \mathrm{Wm}^{-1} \mathrm{~K}^{-1}$. On the negative side, $\mathrm{ScN}$ has a relatively high thermal conductivity ${ }^{83}\left(8.3 \mathrm{Wm}^{-1} \mathrm{~K}^{-1}\right)$, while as $\mathrm{CrN}$ has a low electrical conductivity of approximately $10 \mathrm{~m} \Omega \mathrm{cm}$ prompting additional research. As $\mathrm{ScN}$ and $\mathrm{CrN}$ are abundant compared to traditional thermoelectric materials, they can be proposed for synthesis based on the PGEC method for thermoelectric research. To do this, limited doping of $\mathrm{CrN}$ with vanadium (paper III), plus film nitrogen deficiency and the formation of the secondary phase $\mathrm{Cr}_{2} \mathrm{~N}$ is proposed. Gaul et al. ${ }^{84}$ showed that sub-atomic doping of $\mathrm{Bi}_{2} \mathrm{Te}_{3}$ could lead to a $75 \%$ power-factor enhancement due to highly degenerate and low effective-mass density of States leading to enhance mobility while as Mehta et al. ${ }^{85}$ showed that low-level doping can result in antisite defect suppression, another method which increases charge carrier mobility. 


\section{Theoretical calculations: phase stability and structure prediction}

Modern theoretical methodologies and high-speed computers allow researchers to study and predict the physical and chemical properties of solids directly from the fundamental equations of quantum mechanics and thermodynamics. ${ }^{86} 87$ Experimental research in material science is time consuming and expensive, thus theoretical calculations can be used to guide experimentalists and prevent redundant work.

\section{The Schrödinger equation}

Quantum mechanics provides a theoretical description of the microscopic world. As most states of matter are composed of positively charged nuclei surrounded by negatively charged electrons, quantum mechanics is needed and in principle capable of explaining all material properties. Thus, the Schrödinger equation is considered a great achievement in physics:

$$
\begin{aligned}
& \widehat{H} \Psi=i \hbar \partial \Psi / \partial t \\
& \Psi=\Psi\left(r_{1}, r_{2}, r_{3}, \ldots, R_{1}, R_{2}, R_{3}, \ldots, t\right) \\
& H=-\frac{1}{2} \sum_{i=1}^{n} \frac{\hbar^{2}}{m_{e}} \nabla_{i}^{2}-\frac{1}{2} \sum_{I=1}^{n} \frac{\hbar^{2}}{M_{I}} \nabla_{I}^{2}-\sum_{i, I} \frac{Z_{I} e^{2}}{\left|r_{i}-R_{I}\right|}+\frac{1}{2} \sum_{i \neq j} \frac{e^{2}}{\left|r_{i}-r_{j}\right|}+\frac{1}{2} \sum_{I \neq j} \frac{Z_{I} Z_{J} e^{2}}{\left|R_{I}-R_{J}\right|}
\end{aligned}
$$

where equation 13 is the time-dependent Schrödinger equation, equation 14 is the wave function of the quantum system, consisting of $r_{i}$ (the coordinates of the $i^{\text {th }}$ electron), $R_{I}$ (the coordinates of the $I^{\text {th }}$ nucleus) and $t$ (time). Equation 15 is the Hamiltonian operator. It is needed to describe the energy state of the wave function and consists of five separate terms: the kinetic energy of electrons, the kinetic energy of the nuclei, electron-nucleus attraction, electron-electron repulsion, and 
nucleus-nucleus repulsion. It was this equation and other advances in quantum mechanics that prompted Dirac to announce in 1929 that: "The underlying physical laws necessary for the mathematical theory of a large part of physics and the whole of chemistry are thus completely known, ...", but in real macroscopic materials, $n_{i}$ and $N_{I}$ are close to $10^{23}$ particles, which makes it necessary for us to simplify the equation otherwise "... the difficulty is only that the exact application of these laws leads to equations much too complicated to be soluble". ${ }^{88}$

An approximation used to simplify the problem is the Born-Oppenheimer approximation, where the motion of the electrons and the nuclei are separated when solving for the electronic degrees of freedom. Second, we have the Bloch theorem, which states that due to the periodicity of the crystal lattice, all wave functions must have the same periodicity of the lattice, making it sufficient to only solve the electronic problem for one-unit cell, and then apply periodic boundary conditions. Although both modifications greatly simplify the problem at hand, a typical unit cell may have a hundred electrons which still renders the Schrödinger equation unsolvable. This is where the electronic density becomes useful.

\section{Density Functional Theory (DFT)}

Hohenberg and $\mathrm{Kohn}^{89}$ proposed two theorems fundamental to the density functional theory:

Theorem 1: For any system with interacting particles in an external potential $V_{\text {ext }}(\boldsymbol{r})$, the potential $V_{\text {ext }}(\boldsymbol{r})$ is uniquely determined by the ground state particle density $n_{0}(\boldsymbol{r})$ up to an additive constant.

Theorem 2: A universal functional for the energy $E\left[n, V_{\text {ext }}\right]$ in terms of the density can be defined, valid for any external potential $V_{\text {ext }}(\boldsymbol{r}) . E_{0}=E\left[n_{0}\right]$ is the global energy minima for any particular potential.

In general, instead of determining the allowed energy states by solving the manybody wave function dependent on $3 N$ coordinates $(N$ being the number of 
electrons), an electronic density which only depends on 3 coordinates and uniquely defines the ground state properties of the equivalent many-body system can be used. Any many-body system with an external potential can be defined by a universal functional of energy. Minimizing this functional will lead to the global energy minimum and consequently, the ground state properties of the many-body system.

These theorems have the disadvantage that they do not introduce any universal functional needed to calculate the ground state properties. However, Kohn and Sham ${ }^{90}$ proposed a method in which the many-body electrons are simulated by a fictitious system of non-interacting particles. The fictitious system is constructed such that the energy of these Kohn-Sham (KS) particles is minimized by the same density which minimize the energy of the real electronic system. The Kohn-Sham particle system is described by:

$H_{e f f} \psi_{i}(r)=\left[-\frac{\hbar^{2}}{2 m_{e}} \nabla^{2}+V_{K S}(r)\right] \psi_{i}(r)=\epsilon_{i} \psi_{i}(r)$

where $\hbar$ is the Plank constant, $m_{e}$ is the mass of an electron, $\psi_{i}(r)$ is the KS orbitals, $\epsilon_{i}$ is the KS orbital energy and $V_{K S}$ is defined by the Kohn-Sham approach to the density functional theory:

$$
V_{K S}(r)=V_{e x t}(r)+\int \frac{n\left(r^{\prime}\right)}{\left|r-r^{\prime}\right|} d^{3} r^{\prime}+\frac{\delta E_{x c}[n]}{\delta n(r)}
$$

which consists of the electron-nuclei interaction, the internal energy of a classical repulsive gas, and the electronic quantum effects (the exchange-correlation term) which stems from non-classical electron repulsion and the many-body contribution to the kinetic energy. In this equation, $n(r)$ is the KS particle density and $\psi_{i}$ are the KS orbitals:

$n(r)=\sum_{i=1}^{N}\left|\psi_{i}(r)\right|^{2}$

Thus, we can simulate real material systems based on the fictitious KS system and the KS total energy functional:

$E[n]=T[n]+\int V_{\text {ext }}(r) n(r) d r+\frac{1}{2} \iint \frac{n(r) n\left(r^{\prime}\right)}{\left|r-r^{\prime}\right|} d^{3} r d^{3} r^{\prime}+E_{I I}+E_{x c}[n]$

where $T[n]$ is defined as the independent particle kinetic energy and $E_{I I}$ is defined as the interaction between the nuclei. The second term is the energy from the nuclei, or any other external potential and the third term is the energy of the 
classical repulsive gas (Hartree term). Although the KS pseudosystem shouldn't formally give electron orbitals, these equations are frequently used as a first-round investigation to calculate the electronic band structure and phase stability of hypothetical crystals before moving forward with more complicated methods.

\section{Phase stability}

A group of atoms can be organized in a crystal structure, thus determining the electronic properties. However, for a given set of atoms not all crystal structures are stable. A material system is in thermodynamic equilibrium when under the conditions of a fixed temperature, pressure and number of particles, the Gibbs free energy of the material system is at a minimum:

$G=H-T S$

where $H$ is the formation enthalpy, $T$ is the absolute temperature and $S$ is the entropy.

The enthalpy $H$ is given by

$H=E+P V$

$E$ being the total energy of the system, $P$ the system pressure and $V$ the system volume. According to the Gibbs free energy equation, the system is stable when $G$ is at a minimum. In the case of a hypothetical binary alloy composed of element $A$ and element $B$,

$\Delta G_{\text {mix }}(x)=G(x)-\left(x G_{A}+(1-x) G_{B}\right)$

where $G(x)$ is the free energy of the compound, and $G_{A}$ and $G_{B}$ are the free energy of elements $A$ and $B$ and $x$ being the $A$ element atomic percentage. Therefore, the alloy would be stable compared to the elements if $\Delta G_{\text {mix }}(x)<0$ otherwise it will decompose.

$\Delta G_{\text {mix }}(x)$ can also be expressed by the mixing enthalpy $\Delta H_{\text {mix }}$, and mixing entropy $\Delta S_{\text {mix }}$ to produce:

$\Delta G_{\text {mix }}=\Delta H_{\text {mix }}-T \Delta S_{\text {mix }}$ 
Figure 14 shows the Gibbs free energy for a hypothetical system consisting of phase $\alpha$ and phase $\beta$, both with a fixed and equal composition. Phase $\alpha$ is shown to have a lower Gibbs free energy compared to phase $\beta$, therefore it is more stable. However, phase transformation requires the system to overcome the potential barrier $U$, causing phase $\beta$ to remain in a metastable state. Please note that a lower Gibbs free energy will promote the system to spontaneously undergo transformation but has nothing to say on the required time and transformation rates for the process ${ }^{91}$ which is studied in chemical kinetics. One well-known example is graphite and diamond, which are both pure carbon. Graphite has a lower Gibbs free energy compared to diamond and therefore is stable while as the diamond structure is metastable. However, under standard pressure and temperature conditions and in practice, "diamonds are forever" as the potential barrier preventing diamond phase transformation to graphite is very large and requires time many orders of magnitude longer than the age of the universe.

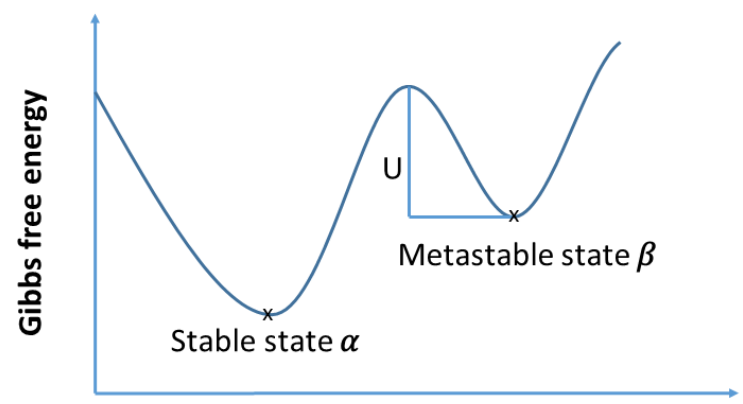

Atomic arrangement

Figure 14. Hypothetical Gibbs free energy for an atomic arrangement in the form of phase $\alpha$ and phase $\beta$. Phase $\alpha$ has a lower Gibbs free energy and is located at the global minimum of the system compared to phase $\beta$ which is located at a local minimum, therefore phase $\alpha$ is stable compared to the metastable phase $\beta$. 
As mentioned previously, DFT calculations are typically performed at $0 \mathrm{~K}$ temperature. The omitted temperature dependence can affect the Gibbs free energy, especially for the case of magnetic material, and may change non-stable phases into stable ones. One good example is chromium nitride which has an antiferromagnetic, orthorhombic structure below $280 \mathrm{~K}$ and transforms into a paramagnetic, face-centered cubic structure at room temperature ${ }^{92}$. Also, vibrational energies which are temperature activated can play a decisive role. However, including temperature is considered a challenge in first-principle calculations, which requires powerful computational resources and advanced methods such as the Monte Carlo technique. Nevertheless, for the case of mixing energies and formation enthalpies, such effects are often small for the right set of material. For example, non-magnetic transition metal nitrides which have very high melting temperatures are decent cases where time consuming temperaturedependent calculations can be avoided in a first round of investigation. ${ }^{93} 94$ Thus, for phase stability calculations the Gibbs free energy global minimum used to determine thermodynamic equilibrium mostly depends on the formation enthalpy of the system:

$G=H=E+P V$

Under normal conditions the pressure $(P)$ is almost zero. In a solid, the internal energy $E$ is composed of a potential energy which originates from atomic interaction and bonding and will be used for constructing an enthalpy diagram.

Figure 15 shows a hypothetical binary enthalpy diagram. It is seen that the formation energy for the compounds are compared to their elemental form. The lowest energy points are connected to each other by the "convex hull", which is defined as a line that encircles all data points without having any concavities.

To calculate the formation enthalpy per atom $\left(H_{\text {atom }}\right)$ the following equation is used:

$H_{\text {atom }}=\left[E_{\text {tot }}-n_{A}\left(E_{\text {min }}^{A}\right)-n_{B}\left(E_{\text {min }}^{B}\right)\right] / n_{A+B}$

where $E_{\text {tot }}$ is the total energy of the compound phase unit cell, $E_{\min }$ is the minimum energy of element $A$ or $B$ and $n$ is the total number of atoms of element $A$ or $B$ in the unit cell. If $H_{\text {atom }}$ for any given compound is negative and located on the convex hull, it will be stable, while the remaining data points located above the hull represent metastable or unstable compounds. 


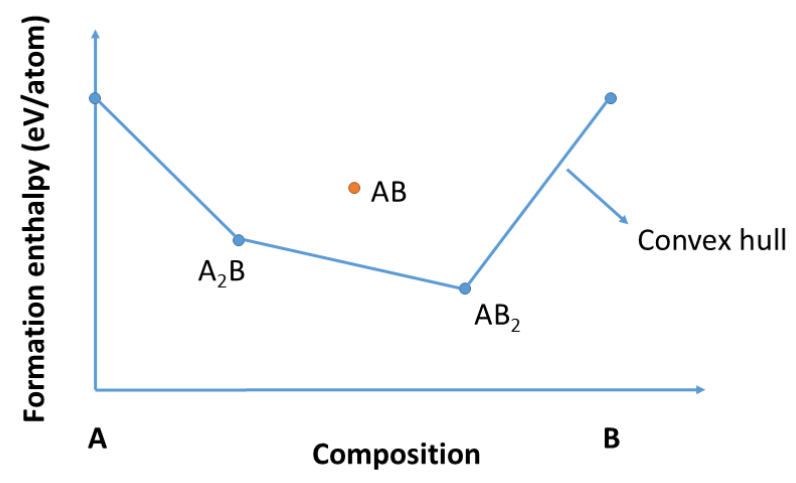

Figure 15. Hypothetical enthalpy diagram of elements $A$ and $B$. The compound mixture in the form of $A_{2} B$ and $A B_{2}$ are located on the convex hull and are stable. However, the AB stoichiometry is not located on the hull and is either metastable or unstable.

\section{Random alloys and order/disorder phase transformation}

In addition to crystalline compounds, solid solutions and random alloys are also of interest when simulating and studying the properties of hypothetical compounds. In an unrealistic scenario, a very large supercell capable of representing the selfaveraging properties of an ideal random alloy is constructed for computer simulations. However, computing limitations require the researcher to scale down the efforts towards modeling material with a minimum short-range ordering (SRO). Such efforts are more realistic as real alloys do display temperature dependent effects such as clustering and ordering.

To perform computer simulations of random alloys (in a reasonable computational time frame), Zunger et al. suggested the special quasirandom structure (SQS) model ${ }^{95}$, were in a binary alloy system, $\mathrm{A}_{\mathrm{x}} \mathrm{B}_{1-\mathrm{x}}$, the A-type and B-type atoms are distributed in the super cell in such a way that short range ordering parameters between both kind of atoms become zero or close to zero, with a focus on short range coordination shells. Figure 16 shows a $3 \mathrm{D}$ model of an $\left(\mathrm{A}_{0.5}, \mathrm{~B}_{0.5}\right) \mathrm{N}$ random alloy generated by the SQS model. 


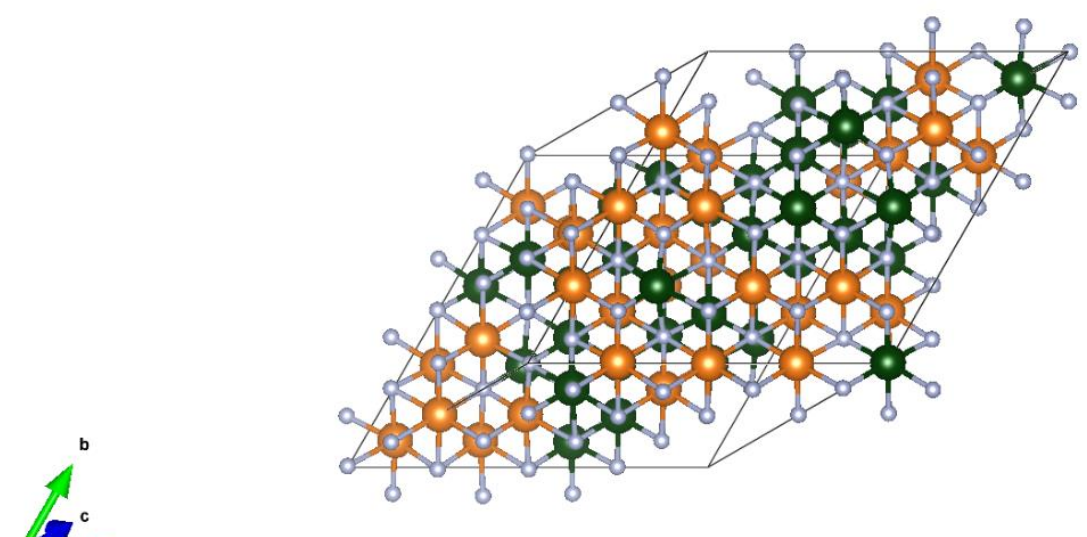

Fig 16. 3D model of an $\left(A_{0.5,} B_{0.5}\right) N$ random alloy crystallized in the rock-salt cubic structure and generated by the $S Q S$ model.

To calculate the order/disorder phase transition temperature, the formation energy of the $\left(M e_{0.5}, A E_{0.5}\right) \mathrm{N}$ random alloy is compared to an ordered structure of the same compound stoichiometry. At the transition temperature between the two phases, the Gibbs free energy is:

$G^{\text {ord }}=G^{\text {dis }}$,

where $G^{\text {ord }}$ and $G^{\text {dis }}$ are the Gibbs free energy of the ordered and disordered structures, respectively. At zero pressure, the above equation becomes:

$$
E^{\text {ord }}=E^{\text {dis }}-T S,
$$

where $\mathrm{T}$ is the transition temperature and $\mathrm{S}$ is the entropy and can be approximated as a disordered random alloy (relative to the ordered structure):

$S=-k_{B}[x \ln x+(1-x) \ln (1-x)]$

In our case, $\mathrm{x}=0.5$ for a $50 / 50$ metal atom ratio. Predicting the transition temperature is important as it can provide insight for the researcher on choosing synthesis/annealing temperatures. 


\section{Simulating equivalent ternaries for scandium nitride}

The aim of conducting theoretical predictions in this thesis is to search for a possible, as yet hypothetical, replacement for scandium nitride. $\mathrm{ScN}$ is a cubic semiconducting hard coating which has gained interest for thermoelectrics. It has an approximate power factor of $\sim 3000 \mu \mathrm{Wm}^{-1} \mathrm{~K}^{-2}$ at $500{ }^{\circ} \mathrm{C}$ which is very high for a transition metal nitride ${ }^{96}$. In addition to the power factor, the thermal conductivity of $\mathrm{ScN}$ is also high (close to $\sim 10 \mathrm{Wm}^{-1} \mathrm{~K}^{-1}$ ) resulting in a low $z T$ value and consequently, low thermoelectric efficiency. While scandium is a reasonably abundant element ${ }^{97}$, it is expensive due to modest demand which limits world production. Also, scandium is an isotopically pure element, which means that phonon scattering due to isotope impurities is absent.

In a paper published in 2014 by Alling ${ }^{98}$, it was proposed that one could search for an equivalent ternary based on $\mathrm{ScN}$. The ternary would have a similar electronic band structure and Seebeck coefficient, while as the substituted elements would be better at phonon scattering. An example would be a naturally layered crystal structure. In his paper, $\mathrm{TiMgN}_{2}$ was chosen, since magnesium and titanium belong to the groups before (group 2) and after (group 4) scandium in the periodic table. The results of the research show that not only $\mathrm{TiMgN}_{2}$ is predicted to be stable, but it is also a semiconductor with a $1.1 \mathrm{eV}$ band gap which crystallizes into the $\mathrm{NaCrS}_{2}$ superstructure (figure 17). This structure can also be described as a $\mathrm{NaCl}$ (B1) based superstructure which includes three alternating layers of titanium and magnesium. Experimental synthesis of such superstructures could be feasible through high-temperature annealing of rock-salt cubic solid solutions and would require X-ray diffraction techniques ${ }^{99}$ and transmission electron microscopy ${ }^{100}$, in order to identify phase transformation. These results open the opportunity to study other replacements for scandium such as zirconium and hafnium, as both elements are heavier than scandium and titanium. They also consist of multiple stable isotopes which may enhance phonon scattering. This is discussed in paper II. 

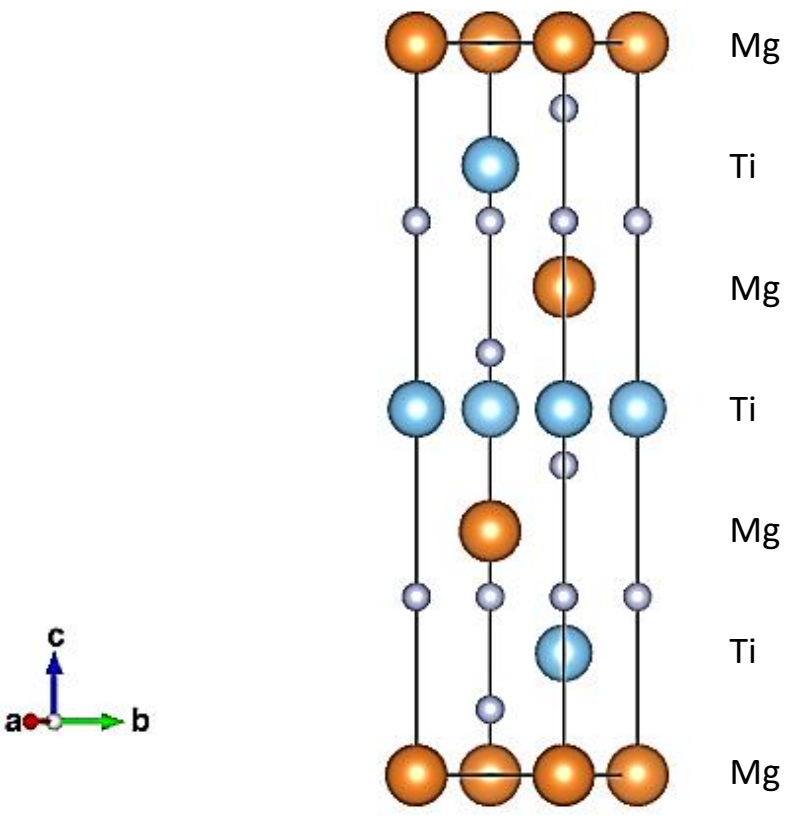

Figure 17. $\mathrm{TiMgN}_{2}$ crystallized into the trigonal $\mathrm{NaCrS} \mathrm{S}_{2}$ superstructure. Note the alternating layers of titanium and magnesium compared to the smaller nitrogen atoms. 


\section{Contributions to the field}

This thesis studies early transition metal nitrides thin films for the purpose of researching novel thermoelectric material. These films were synthesized by reactive magnetron sputtering of elemental targets using a mixture of argon and nitrogen gas and studied through SEM, TEM, EDS, XPS and XRD techniques to name a few. Under a strict definition, only rock-salt cubic chromium nitride ( $\mathrm{CrN})$ is considered a semiconducting transition metal nitride, and thus is the main theme of this study.

The research conducted in this thesis can be divided into two sub-categories: experimental research revolving around the synthesis and characterization of $\mathrm{CrN}$ and its alloys, and the theoretical/experimental research motivated by the thermoelectric properties of rock-salt cubic scandium nitride $(\mathrm{ScN})$, also known for its semiconducting and thermoelectric properties.

The analysis in paper I concludes that epitaxial $\mathrm{CrN}$ thin films show good thermoelectric properties with a high power-factor close to $5000 \mu \mathrm{Wm}^{-1} \mathrm{~K}^{-2}$ at room temperature. The results show that the synthesis process is sensitive to the gas flow ratio as increasing the nitrogen content of the gas flow will introduce multiple grain boundaries. This in turn increases electrical resistivity. On the other hand, decreasing the nitrogen content will result in the formation of a secondary phase of chromium nitride: hexagonal $\mathrm{Cr}_{2} \mathrm{~N}$. Small amounts of $\mathrm{Cr}_{2} \mathrm{~N}$ form in the shape of randomly dispersed nano-inclusions inside a $\mathrm{CrN}$ matrix. The same can also be said for deposition temperature, as too low deposition temperatures increase film surface roughness and grain boundaries by limiting surface diffusion and coalescence while as too high temperatures will cause total phase transformation from rock-salt $\mathrm{CrN}$ to hexagonal $\mathrm{Cr}_{2} \mathrm{~N}$. These studies led to the conclusion that the best thermoelectric properties belong to the phase pure and single crystal $\mathrm{CrN}$ films. Future research would also require thermal conductivity measurements. Although the $\mathrm{Cr}_{2} \mathrm{~N}$ nano-inclusions did not show any improvement in the power factor, studying the effects of these nano-inclusions on the thermal conductivity is also needed.

Paper II provides a more in-depth investigation of hexagonal $\mathrm{Cr}_{2} \mathrm{~N}$. Although $\mathrm{Cr}_{2} \mathrm{~N}$ is a conductor, with limited thermoelectric applications, it is still a material 
worth of study. $\mathrm{Cr}_{2} \mathrm{~N}$ is shown to be deposited as a single crystal, epitaxial film by reactive magnetron sputtering simply through regulating the nitrogen/argon gas flow ratio. A thermal conductivity value of $12 \mathrm{Wm}^{-1} \mathrm{~K}^{-2}$ is relatively low for metals. The proven oxidation resistance, the elastic-plastic behavior, and the silver luster of the film makes $\mathrm{Cr}_{2} \mathrm{~N}$ an interesting candidate material for decorative hard coatings, contact material, capping and diffusion layer applications. Metallic $\mathrm{Cr}_{2} \mathrm{~N}$ can also be introduced as a pure and single crystal layer and thus, $\mathrm{CrN} / \mathrm{Cr}_{2} \mathrm{~N}$ metal/semiconductor superlattices can be envisioned for additional thermoelectric or hard-coating studies.

Although the results from paper I are promising, the figure of merit for single crystal $\mathrm{CrN}$ thin films is estimated to be 0.5 based on published thermal conductivity measurements. Chromium is relatively cheap and abundant, and chromium nitride in comparison with many benchmark thermoelectric material has superior mechanical, chemical and thermal stability, but the figure of merit is medium to low. One proposal to enhance thermoelectric $z T$, is to decrease the electric resistivity by doping and alloying. Rock-salt cubic vanadium nitride (VN) has a very similar lattice parameter ${ }^{101}$ to $\mathrm{CrN}$ (approximately $4.13 \AA$ ), making it possible to alloy $\mathrm{CrN}$ without disrupting the single crystal nature of the film. $(\mathrm{Cr}$, $\mathrm{V}) \mathrm{N}$ alloyed films show that even a small addition of vanadium can greatly reduce the electrical resistivity of the film. However, adding to much (more than $5-10 \%$ ) vanadium to a $(\mathrm{Cr}, \mathrm{V}) \mathrm{N}$ solid solution will cause a decrease in the Seebeck coefficient. Paper III shows that by increasing the deposition temperature to 720 ${ }^{\circ} \mathrm{C}$ and decreasing the nitrogen content of the gas flow to $26 \%$, Seebeck coefficient and power-factor values for pure $\mathrm{CrN}$ averaged around $400 \mu \mathrm{V} / \mathrm{K}$ and $11.4 \times 10^{-3}$ $\mathrm{W} / \mathrm{mK}^{2}$ is obtained. Adding vanadium to reach a certain $\mathrm{V} / \mathrm{Cr}$ atomic ratio of 0.035:1 will reduce the Seebeck coefficient to an average value of $270 \mu \mathrm{V} / \mathrm{K}$, this lower Seebeck coefficient is however compensated by the decreased electrical resistivity, leading to a very large average power-factor value of $9.1 \times 10^{-3} \mathrm{~W} / \mathrm{mK}^{2}$. DFT calculations were also performed to simulate various doping conditions of the nitrogen vacancy and vanadium substitution and how it effects the density of states, showing the possibility to increase both the Seebeck coefficient and the electrical conductivity simultaneously. Although these exceptionally high Seebeck and power-factor values (comparable to that of $\mathrm{Bi}_{2} \mathrm{Te}_{3}$ ) should be taken with caution, the relatively large number of measurements and samples compensate in return and will hopefully generate further interest in $\mathrm{CrN}$ and its alloys as a novel thermoelectric material. 
In addition to the experimental research, the theoretical studies from paper IV showed that $\mathrm{TiMgN}_{2}, \mathrm{ZrMgN}_{2}$ and $\mathrm{HfMgN}_{2}$ which were modeled over cubic scandium nitride all predict stable crystal structures for the given stoichiometries. These results predict that it is possible to synthesize all three compounds and to influence the crystal structure by choosing different substrates as trigonal $\mathrm{NaCrS}_{2}$ and monoclinic $\mathrm{LiUN}_{2}$ both show tendency for stable crystal structure formation. The calculated electronic band structure of these compounds shows a direct bandgap for the monoclinic and an indirect band-gap for the trigonal crystal structures. These findings coupled with predicted Seebeck coefficient absolute values between 400 and $2000 \mu \mathrm{V} / \mathrm{K}$ encourages actual synthesis of such materials.

Similar to (Ti, Mg)N and $\mathrm{TiMgN}_{2}$, theoretical studies on ( $\mathrm{Zr}, \mathrm{Mg}$ ) N and (Hf, $\mathrm{Mg}$ ) N alloys continued in paper $\mathbf{V}$. DFT calculations were used to study $(\mathrm{Zr}, \mathrm{Mg}) \mathrm{N}$ and (Hf, Mg)N alloys based on the SQS model. The transition temperature between the ordered monoclinic structure of $\mathrm{ZrMgN}_{2}$ and $\mathrm{HfMgN}_{2}$ and the disordered $(\mathrm{Zr}$, $\mathrm{Mg}$ ) N and (Hf, Mg)N alloys was calculated to be approximately $800 \mathrm{~K}$ and 1050 $\mathrm{K}$ respectively. Density of State (DoS) calculations show that similar to $(\mathrm{Ti}, \mathrm{Mg}) \mathrm{N}$, $(\mathrm{Zr}, \mathrm{Mg}) \mathrm{N}$ and $(\mathrm{Hf}, \mathrm{Mg}) \mathrm{N}$ are also semiconducting with a band gap of $0.75 \mathrm{eV}$ and $0.92 \mathrm{eV}$ respectively and high Seebeck coefficient values exceeding $\pm 1000 \mu \mathrm{V} / \mathrm{K}$ at room temperature.

Finally, Paper VI is an experimental attempt based on the theoretical conclusions of paper IV, where $(\mathrm{Ti}, \mathrm{Mg}) \mathrm{N}$ thin film alloys were deposited by reactive magnetron sputtering. These films, which were deposited at $400{ }^{\circ} \mathrm{C}$, show fibertexture and are crystallized in the rock-salt cubic structure. As-deposited films show an electrical resistivity of $150 \mathrm{~m} \Omega \mathrm{cm}$ and a Seebeck coefficient of $-25 \mu \mathrm{V} / \mathrm{K}$, which points towards the semiconducting properties of $(\mathrm{Ti}, \mathrm{Mg}) \mathrm{N}$ at the same order of magnitude of seen in $\mathrm{ScN}$. These films when annealed at approximately $800{ }^{\circ} \mathrm{C}$ undergo a phase transformation where nano-inclusions of an $\mathrm{LiTiO}_{2}$-type titanium/magnesium oxynitride/nitride superstructures are formed. The oxygen is due to the porous film where oxygen pockets form between grain boundaries. DFT calculations predict that the oxygen-free $\mathrm{TiMgN}_{2}$ superstructure to have a $0.07 \mathrm{eV}$ direct band-gap.

In conclusion, early transition metal nitride thin films were studied in search of novel thermoelectric material to replace the traditional thermoelectric material 
used today. Transition metal nitrides are well-known for their mechanical, chemical and thermal stability, and are of interest due to their high thermoelectric power-factor. In particular, rock-salt cubic $\mathrm{CrN}$ is shown to have a power-factor value comparable or even greater than that of $\mathrm{Bi}_{2} \mathrm{Te}_{3}$. Further research would propose alloying $\mathrm{CrN}$ by introducing heavy elements such as tantalum, hafnium and tungsten as all three form conducting nitrides. Rock-salt cubic hafnium nitride ( HfN) could prove to be a suitable candidate when considering the relative atomic mass $^{102}$ of hafnium compared to chromium (178.49 vs. 51.99). The relatively heavy elements tantalum and tungsten could potentially form either hexagonal nanoinclusions ( $\mathrm{TaN}$ and $\mathrm{W}_{2} \mathrm{~N}$ ) or accept the rock-salt cubic structure. In any case, the effects of adding such elements to $\mathrm{CrN}$ could alter the electrical resistivity, thermal conductivity and the Seebeck coefficient value. The synthesis of $\mathrm{CrN} /(\mathrm{Cr}$, V)N superlattices should also be considered as a means to reduce thermal conductivity by introducing quasi-random layer thickness in order to enhance interface phonon scattering. In addition to thin film research, synthesis of substoichiometric and single crystal $\mathrm{CrN}$ can be considered as a very interesting research topic in thermoelectrics.

As for the $(\mathrm{Ti}, \mathrm{Mg}) \mathrm{N},(\mathrm{Zr}, \mathrm{Mg}) \mathrm{N}$ and ( $\mathrm{Hf}, \mathrm{Mg}) \mathrm{N}$ alloys, synthesizing these ternaries in either the trigonal $\mathrm{NaCrS}_{2}$ or the monoclinic $\mathrm{LiUN}_{2}$ structures could be possible by methods such as DC reactive magnetron sputtering which synthesizes material far from thermodynamic equilibrium. Actual synthesis would require a UHV chamber, suitable substrates according to their crystal structure and lattice parameter (e.g., hexagonal $\mathrm{GaN}$, hexagonal $\mathrm{SiC}$...) and the required elemental targets $(\mathrm{Mg}, \mathrm{Ti}, \mathrm{Zr}$, and $\mathrm{Hf}$ ). The synthesis of these ternaries could lead to power factors similar or better than $\mathrm{ScN}$ but with lower thermal conductivities. The experience gained from annealing $(\mathrm{Ti}, \mathrm{Mg}) \mathrm{N}$ could continue by focusing on the synthesis and annealing of denser and oxygen-free thin films, preferably at higher temperatures. 


\section{Bibliography}

${ }^{1}$ T. J. Brown, N. E. Idoine, E. R. Raycraft, S. F. Hobbs, R. A. Shaw, P. Everett, C. Kresse, E. A. Deady and T. Bide, World Mineral Production 2013-2017: British Geological Survey (2019) Keyworth, Nottingham.

${ }^{2}$ R. Amatya and R. J. Ram, Trend for Thermoelectric Materials and Their Earth Abundance, J. Electr. Mater. 41 (2012) 1011-1019.

${ }^{3}$ R. Enright, S. Lei, G. Cunningham, I. Mathews, R. Frizzell and A. Shen, Integrated Thermoelectric Cooling for Silicon Photonics, ECS J. Solid State Sci. Technol. 6 (2017) 3103-3112.

${ }^{4}$ V. Semeniuk and D Protsenko, Optimal Integration of Cascade Thermoelectric Cooler into Electronic Housing: Experimental Approach, J. Electron. Mater. 47 (2018) 32823287.

${ }^{5}$ D. M. Rowe, Applications of nuclear-powered thermoelectric generators in space, Appl. Energy 40 (1991) 241-271.

${ }^{6}$ R. C. O'Brien, R. M. Ambrosi, N. P. Bannister, S. D. Howe and H. V. Atkinson, Safe radioisotope thermoelectric generators and heat sources for space applications, J. Nucl. Mater. 377 (2008) 506-521.

${ }^{7}$ M. J. Dougherty, Camouflage At War: An Illustrated Guide from 1914 to the Present Day (2017) Amber Books.

${ }^{8}$ Active adaptive thermal stealth system: US patent US8080792B2.

${ }^{9}$ T. M. Tritt, Thermoelectric Phenomena, Materials, and Applications, Annu. Rev. Mater. Res. 41 (2011) 433-448.

${ }^{10} \mathrm{~J}$. Yang and T. Caillat, Thermoelectric Materials for Space and Automotive Power Generation, MRS Bull. 31 (2006) 224-229.

${ }^{11}$ L. E. Toth, Transition Metal Carbides and Nitrides (1971) Academic Press.

12 S. T. Oyama, Chemistry of Transition Metal Carbides and Nitrides (1996) Springer.

13 J. E. Sundgren, Structure and properties of TiN coatings, Thin Solid Films 128 (1985) 21-44.

${ }^{14}$ L. Hultman, Thermal stability of nitride thin films, Vacuum 57 (2000) 1-30.

15 P. H. Mayrhofer, C. Mitterer, L. Hultman and H. Clemens, Microstructural design of hard coatings, Prog. Mater. Sci. 51 (2006) 1032-1114.

${ }^{16}$ A. Hörling, L. Hultman, M. Odén, J. Sjölén and L. Karlsson, Mechanical properties and machining performance of $\mathrm{Ti}_{1-\mathrm{x}} \mathrm{Al}_{\mathrm{x}} \mathrm{N}$-coated cutting tools, Surf. Coat. Technol. 191 (2005) 384-392.

${ }^{17}$ L. Hultman, J. Bareno, A. Flink, H. Söderberg, K. Larsson, V. Petrova, M. Odén, J. E. Greene and I. Petrov, Interface structure in superhard TiN-SiN nanolaminates and nanocomposites: Film growth experiments and ab initio calculations, Phys. Rev. B 75 (2007) 155437. 
${ }^{18}$ P. V. Burmistrova, D. N. Zakharov, T. Favaloro, A. Mohammed, E. A. Stach, A. Shakouri, T. D. Sands, Effect of deposition pressure on the microstructure and thermoelectric properties of epitaxial $\mathrm{ScN}(001)$ thin films sputtered onto $\mathrm{MgO}(001)$ substrates, J. Mater. Res. 30 (2015) 626-634.

${ }^{19}$ N. Tureson, M. Marteau, T. Cabioch, N. V. Nong, J. Jensen, J. Lu, G. Greczynski, D. Fournier, N. Singh, A. Soni, L. Belliard, P. Eklund and A. le Febvrier, Effect of ionimplantation-induced defects and $\mathrm{Mg}$ dopants on the thermoelectric properties of ScN, Phys. Rev. B 98 (2018) 205307.

${ }^{20}$ B. Biswas and B. Saha, Development of semiconducting ScN, Phys. Rev. Mater. 3 (2019) 020301.

${ }^{21}$ P. V. Burmistrova, J. Maassen, T. Favaloro, B. Saha, S. Salamat, Y. R. Koh, M. S. Lundstrom, A. Shakouri and T. D. Sands, Thermoelectric properties of epitaxial ScN films deposited by reactive magnetron sputtering onto $\mathrm{MgO}(001)$ substrates, J. Appl. Phys. 113 (2013) 153704.

${ }^{22}$ S. Kerdsongpanya, B. Sun, F. Eriksson, J. Jensen, J. Lu, Y. K. Koh, N. V. Nong, B. Balke, B. Alling and P. Eklund, Experimental and theoretical investigation of $\mathrm{Cr}_{1-x} \mathrm{Sc}_{x} \mathrm{~N}$ solid solutions for thermoelectrics, J. Appl. Phys. 120 (2016) 215103.

${ }^{23}$ S. Kerdsongpanya, O. Hellman, B. Sun, Y. K. Koh, J. Lu, N. V. Nong, S. I. Simak, B. Alling and P. Eklund, Phonon Thermal Conductivity of Scandium Nitride for Thermoelectrics from First-Principles Calculations and Thin-Film Growth, Phys. Rev. B, 96 (2017) 195417. ${ }^{24}$ S. Williams, J. L. Tipper, E. Ingham, M. H. Stone and J. Fisher, In vitro analysis of the wear, wear debris and biological activity of surface-engineered coatings for use in metal-on-metal total hip replacements, Proc. Instn Mech. Engrs 217 (2003) 155-163. ${ }^{25}$ P. Hones, N. Martin, M. Regula and F. Lévy, Structural and mechanical properties of chromium nitride, molybdenum nitride, and tungsten nitride thin films, J. Phys. D: Appl. Phys. 36 (2003) 1023-1029.

${ }^{26}$ C. Constantin, M. B. Haider, D. Ingram and A. R. Smith, Metal/semiconductor phase transition in chromium nitride(001) grown by rf-plasma-assisted molecular-beam epitaxy, Appl. Phys. Lett. 85 (2004) 6371-6373.

27 D. Gall, C.-S. Shin, R. T. Haasch, I. Petrov and J. E. Greene, Band gap in epitaxial NaClstructure CrN(001) layers, J. Appl. Phys. 91 (2002) 5882-5886.

${ }^{28}$ B. Alling, T. Marten and I. A. Abrikosov, Effect of magnetic disorder and strong electron correlations on the thermodynamics of CrN, Phys. Rev. B 82 (2010) 184430.

${ }^{29}$ A. Herwadkar and W. R. L. Lambrecht, Electronic structure of $\mathrm{CrN}$ : A borderline Mott insulator, Phys. Rev. B 79 (2009) 035125.

30 J. D. Browne, P. R. Liddell, R. Street and T. Mills, An investigation of the antiferromagnetic transition of CrN, Phys. Status Solidi A 1 (1970) 715-723.

${ }^{31}$ L. Swadźba, A. Maciejny, B. Formanek, P. Liberski, P. Podolski, B. Mendala, H. Gabriel and A. Poznańska, Influence of coatings obtained by PVD on the properties of aircraft compressor blades, Surf. Coat. Technol. 78 (1996) 137-143.

32 P. Panjan, B. Navinšek, A. Cvelbar, A. Zalar and I. Milošev, Oxidation of TiN, ZrN, TiZrN, $\mathrm{CrN}, \mathrm{TiCrN}$ and $\mathrm{TiN} / \mathrm{CrN}$ multilayer hard coatings reactively sputtered at low temperature, Thin Solid Films 282 (1996) 298-301. 
${ }^{33}$ B. Saha, J. A. Perez-Taborda, J. -H. Bahk, Y. R. Koh, A. Shakouri, M. Martin-Gonzalez and T. D. Sands, Temperature-dependent thermal and thermoelectric properties of $n$ type and p-type $\mathrm{Sc}_{1-x} \mathrm{Mg}_{x} \mathrm{~N}$, Phys. Rev. B 97 (2018) 085301.

${ }^{34}$ B. Saha, M. Garbrecht, J. A. Perez-Taborda, M. H. Fawey, Y. R. Koh, A. Shakouri, M. Martin-Gonzalez, L. Hultman and T. D. Sands, Compensation of native donor doping in ScN: Carrier concentration control and p-type ScN, Appl. Phys. Lett. 110 (2017) 252104. ${ }^{35}$ A. le Febvrier, N. V. Nong, G. Abadias and P. Eklund, P-type Al-doped Cr-deficient CrN thin films for thermoelectrics, Appl. Phys. Express 11 (2018) 051003.

${ }^{36}$ C. X. Quintela, J. P. Podkaminer, M. N. Luckyanova, T. R. Paudel, E. L. Thies, D. A. Hillsberry, D. A. Tenne, E. Y. Tsymbal, G. Chen, C. B. Eom and F. Rivadulla, Epitaxial CrN Thin Films with High Thermoelectric Figure of Merit, Adv. Mater. 27 (2015) 3032-3037. ${ }^{37}$ C. X. Quintela, B. Rodríguez-González and F. Rivadulla, Thermoelectric properties of heavy-element doped CrN, Appl. Phys. Lett. 104 (2014) 022103.

${ }^{38} \mathrm{~K}$. Jagannadham, Thermal conductivity of nitride films of $\mathrm{Ti}, \mathrm{Cr}$, and $\mathrm{W}$ deposited by reactive magnetron sputtering, J. Vac. Sci. Technol. A 33 (2015) 031514.

${ }^{39}$ I. Stockem, A. Bergman, A. Glensk, T. Hickel, F. Körmann, B. Grabowski, J. Neugebauer and B. Alling, Anomalous Phonon Lifetime Shortening in Paramagnetic CrN Caused by Spin-Lattice Coupling: A Combined Spin and Ab Initio Molecular Dynamics Study, Phys. Rev. Lett. 121 (2018) 125902.

${ }^{40}$ P. M. Martin, Handbook of deposition technologies for films and coatings: science, applications and technology (2010) Elsevier, third edition.

${ }^{41}$ W. R. Grove, On the electro-chemical polarity of gases, Phil. Trans. Royal Soc. 142 (1852) 87-101.

42 H. Geng, Semiconductor Manufacturing Handbook (2004) McGraw-Hill.

${ }^{43}$ K. Schade, Mikroelektroniktechnologie (1991) Verlag Technik.

${ }^{44} \mathrm{~K}$. Jousten, Handbook of vacuum technology (2008) Wiley-VCH.

${ }^{45}$ C. Kittel, Introduction to Solid State Physics (2004) John Wiley and Sons, eighth edition.

${ }^{46}$ D. L. Smith, Thin-Film Deposition: Principles \& Practice (1995) McGraw-Hill.

${ }^{47}$ D. Depla and S. Mahieu, Reactive Sputter Deposition (2008) Springer-Verlag.

${ }^{48}$ M. Ohring, Materials Science of Thin Films (1992) Academic Press.

${ }^{49}$ M. L. Royer, Recherches expérimentales sur l'épitaxie ou orientation mutuelle de cristaux d'espèces différentes, Bull. Soc. Franç. Minéral. 51 (1928) 7-159.

${ }^{50} \mathrm{M}$. Volmer and A. Weber, Keimbildung in übersättigten Gebilden, Z. Phys. Chem. 119, (1926) 277-301.

${ }^{51}$ F. C. Frank and J. H. van der Merwe, One-dimensional dislocations. I. Static theory, Proc. Roy. Soc. London A 198 (1949) 205-216.

${ }^{52}$ F. C. Frank and J. H. van der Merwe, One-dimensional dislocations. II. Misfitting monolayers and oriented overgrowth, Proc. Roy. Soc. London A 198 (1949) 216-225. ${ }^{53} \mathrm{~F}$. C. Frank and J. H. van der Merwe, One-dimensional dislocations III. Influence of the second harmonic term in the potential representation, on the properties of the model, Proc. Roy. Soc. London A 200 (1949) 125-134. 
54 I. N. Stranski and L. Krastanov, Zur Theorie der orientierten Ausscheidung von lonenkristallen aufeinander, Sitzungsber. Akad. Wiss. Wien. Math.-Naturwiss. 146 (1938) 797-810.

${ }^{55}$ I. Petrov, P. B. Barna, L. Hultman and J. E. Greene, Microstructural evolution during film growth, J. Vac. Sci. Technol. A 21 (2003) S117-S128.

${ }^{56}$ B. A. Movchan and A. V. Demchishin, Structure and properties of thick condensates of nickel, titanium, tungsten, aluminum oxides, and zirconium dioxide in vacuum (in Russian), Fiz. Metal. Metalloved. 28 (1969) 653-660.

$57 \mathrm{~J}$. A. Thornton, Influence of apparatus geometry and deposition conditions on the structure and topography of thick sputtered coatings, J. Vac. Sci. Technol. 11 (1974) 666670.

$58 \mathrm{~J}$. A. Thornton, Influence of substrate temperature and deposition rate on structure of thick sputtered Cu coatings, J. Vac. Sci. Technol. 12 (1975) 830-835.

${ }^{59}$ R. Messier, A. P. Giri and R. A. Roy, Revised structure zone model for thin film physical structure, J. Vac. Sci. Technol. A 2 (1984) 500-503.

${ }^{60}$ P. B. Barna and M. Adamik, Fundamental structure forming phenomena of polycrystalline films and the structure zone models, Thin Solid Films 317 (1998) 27-33.

${ }^{61}$ H. J. Goldsmid, Introduction to Thermoelectricity (2010) Springer.

${ }^{62}$ H. S. Kim, W. Liu, G. Chen, C. -W. Chu and Z. Ren, Relationship between thermoelectric figure of merit and energy conversion efficiency, PNAS 112 (2015) 8205-8210.

${ }^{63}$ B. Paul, J. L. Schroeder, S. Kerdsongpanya, N. V. Nong, N. Schell, D. Ostach, J. Lu, J. Birch and Per Eklund, Mechanism of Formation of the Thermoelectric Layered Cobaltate $\mathrm{Ca}_{3} \mathrm{CO}_{4} \mathrm{O}_{9}$ by Annealing of $\mathrm{CaO}-\mathrm{CoO}$ Thin Films, Adv. Electron. Mater. 1 (2015) 1400022.

${ }^{64}$ A. le Febvrier, N. Tureson, N. Stilkerich, G. Greczynski and P. Eklund, Effect of impurities on morphology, growth mode, and thermoelectric properties of (1 111 ) and (0 0 1) epitaxial-like ScN films, J. Phys. D: Appl. Phys. 52 (2018) 035302.

${ }^{65}$ G. J. Snyder and E. S. Toberer, Complex thermoelectric materials, Nat. Mater. 7 (2008) 105-114.

${ }^{66}$ N. W. Snyder, Energy Conversion for Space Power (1961) Academic Press.

${ }^{67}$ Y. I. Ravich, B. A. Efimova and I. A. Smirnov, Semiconducting Lead Chalcogenides (1970) Springer.

${ }^{68}$ D. Vasilevskiy, R. A. Masut and S. Turenne, Thermoelectric and Mechanical Properties of Novel Hot-Extruded PbTe n-Type Material, J. Elec. Mater. 41 (2012) 1057-1061.

${ }^{69}$ R. G. Lange and W. P. Carroll, Review of recent advances of radioisotope power systems, Energy Convers. Manag. 49 (2008) 393-401.

${ }^{70}$ V. V. Gusev, A. A. Pustovalov, N. N. Rybkin, L. I. Anatychuk, B. N. Demchuk, I. Yu. Ludchak, Milliwatt-Power Radioisotope Thermoelectric Generator (RTG) Based on Plutonium-238, J. Electron. Mater. 40 (2011) 807-811.

${ }^{71}$ D. M. Rowe, CRC Handbook of Thermoelectrics (1995) CRC press.

${ }^{72}$ A. Shakouri, Recent Developments in Semiconductor Thermoelectric Physics and Materials, Annu. Rev. Mater. Res. 41 (2011) 399-431.

${ }^{73}$ B. C. Sales, B. C. Chakoumakos and D. Mandrus, Thermoelectric properties of thalliumfilled skutterudites, Phys. Rev. B 61 (2000) 2475-2481. 
${ }^{74}$ W. Kim, J. Zide, A. Gossard, D. Klenov, S. Stemmer, A. Shakouri and A. Majumdar, Thermal Conductivity Reduction and Thermoelectric Figure of Merit Increase by Embedding Nanoparticles in Crystalline Semiconductors, Phys. Rev. Lett. 96 (2006) 045901.

${ }^{75}$ W. Kim, S. L. Singer, A. Majumdar, D. Vashaee, Z. Bian, A. Shakouri, G. Zeng, J. E. Bowers, J. M. O. Zide and A. C. Gossard, Cross-plane lattice and electronic thermal conductivities of ErAs:InGaAs/InGaAlAs superlattices, Appl. Phys. Lett. 88 (2006) 242107. 76 J. L. Schroeder, D. A. Ewoldt, R. Amatya, R. J. Ram, A. Shakouri and T. D. Sands, BulkLike Laminated Nitride Metal/Semiconductor Superlattices for Thermoelectric Devices, J. Microelectromech. S. 23 (2014) 672-680.

${ }^{77}$ B. Saha, Y. R. Koh, J. Comparan, S. Sadasivam, J. L. Schroeder, M. Garbrecht, A. Mohammed, J. Birch, T. Fisher, A. Shakouri and T. D. Sands, Cross-plane thermal conductivity of $(\mathrm{Ti}, \mathrm{W}) \mathrm{N} /(\mathrm{Al}, \mathrm{Sc}) \mathrm{N}$ metal/semiconductor superlattices, Phys. Rev. B 93 (2016) 045311.

${ }^{78}$ V. Rawat, Y. K. Koh, D. G. Cahill and T. D. Sands, Thermal conductivity of (Zr,W)N/ScN metal/semiconductor multilayers and superlattices, J. Appl. Phys. 105 (2009) 024909. ${ }^{79}$ C. Chiritescu, D. G. Cahill, N. Nguyen, D. Johnson, A. Bodapati, P. Keblinski and P. Zschack, Ultralow Thermal Conductivity in Disordered, Layered WSe ${ }_{2}$ Crystals, Science 315 (2007) 351-353.

${ }^{80}$ P. Jood, R. J. Mehta, Y. Zhang, G. Peleckis, X. Wang, R. W. Siegel, T. Borca-Tasciuc, S. X. Dou and G. Ramanath, Al-Doped Zinc Oxide Nanocomposites with Enhanced Thermoelectric Properties, Nano Lett. 11 (2011) 4337-4342.

${ }^{81}$ S. Kerdsongpanya, N. V. Nong, N. Pryds, A. Žukauskaitė, J. Jensen, J. Birch, J. Lu, L. Hultman, G. Wingqvist and P. Eklund, Anomalously high thermoelectric power factor in epitaxial ScN thin films, Appl. Phys. Lett. 99 (2011) 232113.

82 P. Eklund, S. Kerdsongpanya and B. Alling, Transition-metal-nitride-based thin films as novel energy harvesting materials, J. Mater. Chem. C 4 (2016) 3905-3914.

${ }^{83}$ S. W. King, R. F. Davis and R. J. Nemanich, Gas source molecular beam epitaxy of scandium nitride on silicon carbide and gallium nitride surfaces, J. Vac. Sci. Technol. A 32 (2014) 061504.

${ }^{84}$ A. Gaul, Q. Peng, D. J. Singh, T. Borca-Tasciuc and G. Ramanath, Divalent dopinginduced thermoelectric power factor increase in $\mathrm{p}$-type $\mathrm{Bi}_{2} \mathrm{Te}_{3}$ via electronic structure tuning, J. Appl. Phys. 125 (2019) 165101.

${ }^{85}$ R. J. Mehta, Y. Zhang, H. Zhu, D. S. Parker, M. Belley, D. J. Singh, R. Ramprasad, T. Borca-Tasciuc and Ganpati Ramanath, Seebeck and Figure of Merit Enhancement in Nanostructured Antimony Telluride by Antisite Defect Suppression through Sulfur Doping, Nano Lett. 12 (2012) 4523-4529.

${ }^{86}$ S. Curtarolo, G. L. W. Hart, M. B. Nardelli, N. Mingo, S. Sanvito and O. Levy, The highthroughput highway to computational materials design, Nat. Mater. 12 (2013) 191-201. ${ }^{87}$ R. M. Martin, Electronic Structure: Basic Theory and Practical Methods (2004) Cambridge University Press.

88 P. A. M. Dirac, Quantum mechanics of many-electron systems, Proc. Roy. Soc. London A 123, (1929) 714-733. 
${ }^{89}$ P. Hohenberg and W. Kohn, Inhomogeneous Electron Gas, Phys. Rev. 136 (1964) B864-871.

${ }^{90} \mathrm{~W}$. Kohn and L. J. Sham, Self-consistent equations including exchange and correlation effects, Phys Rev. 140 (1965) A1133-1138.

${ }^{91}$ D. A. Porter and K. E. Easterling, Phase Transformations in Metals and Alloys (1992) Springer-Science + Business Media, B.V., second edition.

92 J. D. Browne, P. R. Liddell, R. Street and T. Millis, An investigation of the antiferromagnetic transition of CrN, Phys. Status Solidi 1 (1970) 715-723.

${ }_{93} \mathrm{M}$. Dahlqvist, B. Alling and J. Rosén, Stability trends of MAX phases from first principles, Phys. Rev. B 81 (2010) 220102(R).

${ }^{94}$ A. Thore, M. Dahlqvist, B. Alling and J. Rosén, Temperature dependent phase stability of nanolaminated ternaries from first-principles calculations, Comp. Mater. Sci. 91 (2014) 251-257.

${ }^{95}$ A. Zunger, S. -H. Wei, L. G. Ferreira and J. E. Bernard, Special Quasirandom Structures, Phys. Rev. Lett. 65 (1990) 353-356.

${ }^{96}$ P. V. Burmistrova, D. N. Zakharov, T. Favaloro, A. Mohammed, E. A. Stach, A. Shakouri, T. D. Sands, Effect of deposition pressure on the microstructure and thermoelectric properties of epitaxial $\mathrm{ScN}(001)$ thin films sputtered onto $\mathrm{MgO}(001)$ substrates, J. Mater. Res. 30 (2015) 626-634.

${ }^{97}$ R. Amatya and R. J. Ram, Trend for Thermoelectric Materials and Their Earth Abundance, J. Elec. Mater. 41 (2012) 1011-1019.

${ }^{98} \mathrm{~B}$. Alling, Metal to semiconductor transition and phase stability of $\mathrm{Ti}_{1-x} \mathrm{Mg}_{\mathrm{x}} \mathrm{Ny}$ alloys investigated by first-principles calculations, Phys. Rev. B 89 (2014) 085112.

${ }_{99} \mathrm{M}$. Birkholz, Thin film analysis by x-ray scattering (2006) Wiley-VCH.

${ }^{100}$ D. B. Williams and C. B. Carter, Transmission electron microscopy: a textbook for materials science (2009) Springer, second edition.

${ }^{101}$ H. O. Pierson, Handbook of Refractory Carbides and Nitrides: Properties, Characteristics, Processing and Applications (1996) Noyes Publications.

102 J. Meija, T. B. Coplen, M. Berglund, W. A. Brand, P. De Bièvre, M. Gröning, N. E. Holden, J. Irrgeher, R. D. Loss, T. Walczyk and T. Prohaska, Atomic weights of the elements 2013 (IUPAC Technical Report), Pure Appl. Chem. 88 (2016) 265-291. 


\section{List of included papers}

\section{Microstructure and thermoelectric properties of $\mathrm{CrN}$ and $\mathrm{CrN} / \mathrm{Cr}_{2} \mathrm{~N}$ thin films}

M. A. Gharavi ${ }^{1}$, S. Kerdsongpanya ${ }^{1,2}$, S. Schmidt ${ }^{1}$, F. Eriksson ${ }^{1}$, N. V. Nong ${ }^{3}$, J. $\mathrm{Lu}^{1}$, B. Balke ${ }^{4}$, D. Fournier ${ }^{5}$, L. Belliard ${ }^{5}$, A. le Febvrier ${ }^{1}$, C. Pallier ${ }^{1}$ and P. Eklund $^{1}$

${ }^{1}$ Thin Film Physics Division, Department of Physics, Chemistry and Biology (IFM),

Linköping University, SE-581 83 Linköping, Sweden

${ }^{2}$ Department of Materials Science and Engineering, Rensselaer Polytechnic Institute, Troy, New York, 12180, USA

${ }^{3}$ Department of Energy Conversion and Storage, Technical University of Denmark, DK4000 Roskilde, Denmark

${ }^{4}$ Institute of Inorganic and Analytical Chemistry, Johannes Gutenberg University, D55131 Mainz, Germany

${ }^{5}$ Institut des NanoSciences de Paris, Sorbonne Universités, UPMC Universités Paris 06, UMR 7588, Paris F-75005, France

J. Phys. D: Appl. Phys. 51 (2018) 355302

\section{Synthesis and characterization of single-phase epitaxial $\mathrm{Cr}_{2} \mathrm{~N}$ thin films by reactive magnetron sputtering}

M. A. Gharavi ${ }^{1}$, G. Greczynski ${ }^{1}$, F. Eriksson ${ }^{1}$, J. Lu $^{1}$, B. Balke ${ }^{2}$, D. Fournier ${ }^{3}$, A. le Febvrier ${ }^{1}$, C. Pallier ${ }^{1}$ and P. Eklund ${ }^{1}$

${ }^{1}$ Thin Film Physics Division, Department of Physics, Chemistry and Biology (IFM),

Linköping University, SE-581 83 Linköping, Sweden

${ }^{2}$ Institute of Inorganic and Analytical Chemistry, Johannes Gutenberg University, D55131 Mainz, Germany

${ }^{3}$ Institut des NanoSciences de Paris, Sorbonne Universités, UPMC Universités Paris 06, UMR 7588, Paris F-75005, France

J. Mater. Sci. 54 (2019) 1434-1442 
High thermoelectric power-factor with enhanced electrical conductivity of chromium nitride thin films by vanadium doping

M. A. Gharavi ${ }^{1}$, D. Gambino ${ }^{2}$, F. Eriksson ${ }^{1}$, A. le Febvrier ${ }^{1}$, R. Armiento ${ }^{2}$, B. Alling $^{2}$ and P. Eklund ${ }^{1}$

${ }^{1}$ Thin Film Physics Division, Department of Physics, Chemistry and Biology (IFM),

Linköping University, SE-581 83 Linköping, Sweden

${ }^{2}$ Theory and Modelling Division, Department of Physics, Chemistry and Biology (IFM),

Linköping University, SE-581 83 Linköping, Sweden

Manuscript in final preparation

\title{
Theoretical study of phase stability, crystal and electronic structure of $\mathrm{MeMgN}_{2}(\mathrm{Me}=\mathrm{Ti}, \mathrm{Zr}$, Hf $)$ compounds
}

\author{
M. A. Gharavi ${ }^{1}$, R. Armiento ${ }^{2}$, B. Alling ${ }^{1,3}$ and P. Eklund ${ }^{1}$ \\ ${ }^{1}$ Thin Film Physics Division, Department of Physics, Chemistry and Biology (IFM), \\ Linköping University, SE-581 83 Linköping, Sweden \\ ${ }^{2}$ Theory and Modelling Division, Department of Physics, Chemistry and Biology (IFM), \\ Linköping University, SE-581 83 Linköping, Sweden \\ ${ }^{3}$ Max-Planck-Institut für Eisenforschung GmbH, D-40237 Düsseldorf, Germany \\ J. Mater. Sci. 53 (2018) 4294-4305
}

\section{Theoretical Study of the Phase Transitions and Electronic Structure of $\left(\mathrm{Zr}_{0.5}, \mathrm{Mg}_{0.5}\right) \mathrm{N}$ and $\left(\mathrm{Hf}_{0.5}, \mathrm{Mg}_{0.5}\right) \mathrm{N}$}

\author{
M. A. Gharavi ${ }^{1}$, R. Armiento ${ }^{2}$, B. Alling ${ }^{2}$ and P. Eklund ${ }^{1}$ \\ ${ }^{1}$ Thin Film Physics Division, Department of Physics, Chemistry and Biology (IFM), \\ Linköping University, SE-581 83 Linköping, Sweden \\ ${ }^{2}$ Theory and Modelling Division, Department of Physics, Chemistry and Biology (IFM), \\ Linköping University, SE-581 83 Linköping, Sweden \\ Manuscript in final preparation
}




\section{Phase Transformation and Superstructure Formation in $\left(\mathrm{Ti}_{0.5}, \mathrm{Mg}_{0.5}\right) \mathrm{N}$ Thin}

\section{Films Through High-Temperature Annealing}

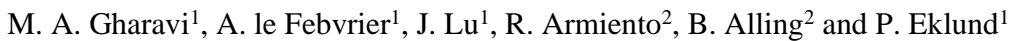

${ }^{1}$ Thin Film Physics Division, Department of Physics, Chemistry and Biology (IFM),

Linköping University, SE-581 83 Linköping, Sweden

${ }^{2}$ Theory and Modelling Division, Department of Physics, Chemistry and Biology (IFM),

Linköping University, SE-581 83 Linköping, Sweden

Manuscript in final preparation 


\section{Papers}

The papers associated with this thesis have been removed for copyright reasons. For more details about these see:

http://urn.kb.se/resolve?urn=urn:nbn:se:liu:diva-161644 


\section{FACULTY OF SCIENCE AND ENGINEERING}

Linköping Studies in Science and Technology, Dissertation No. 2031, 2019

Department of Physies, Chemistry, and Biology (IFM)

Linköping University

SE-581 83 Linköping, Sweden

www.liu.se

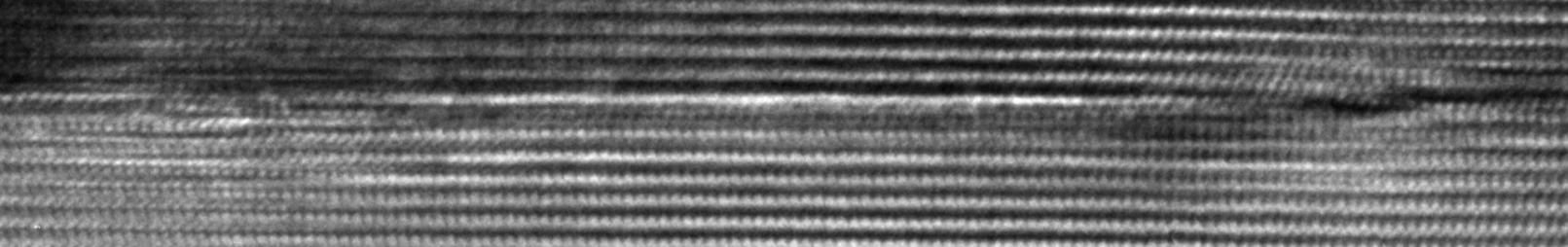
jos

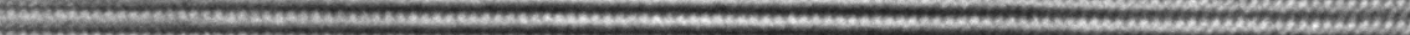

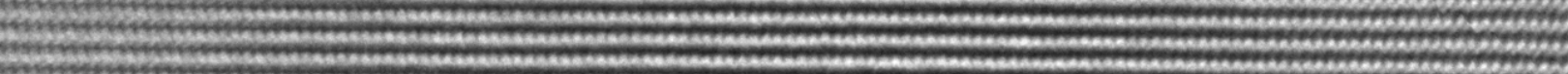

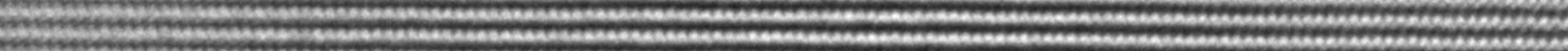

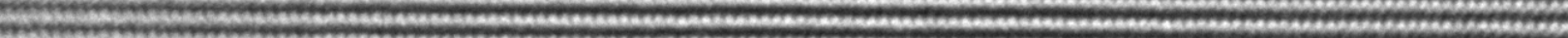

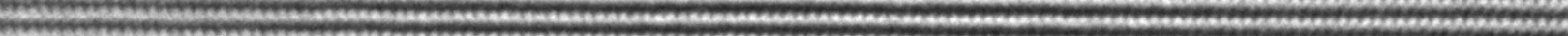

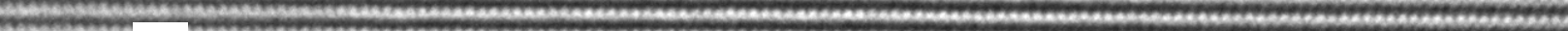

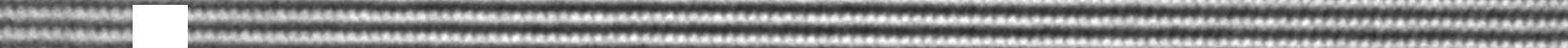

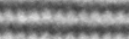

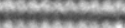

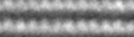

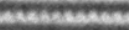

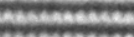

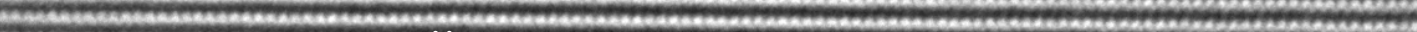

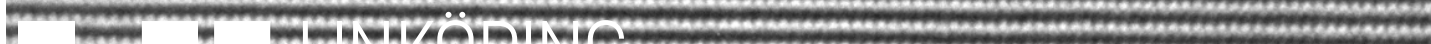

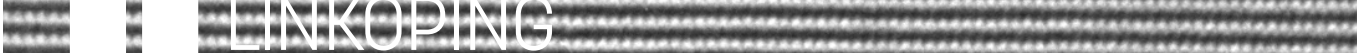

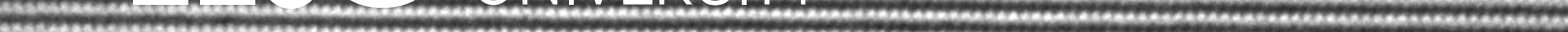

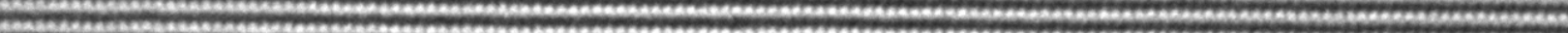

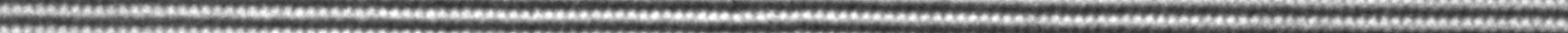

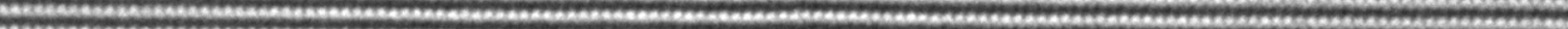

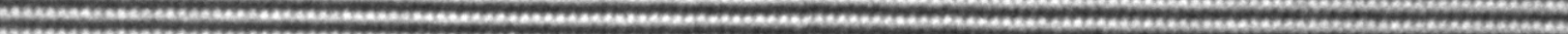

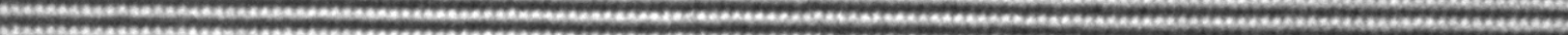

